Discussion Paper No. 12-028

\title{
Resale Price Maintenance and Manufacturer Competition for Retail Services
}

Matthias Hunold and Johannes Muthers

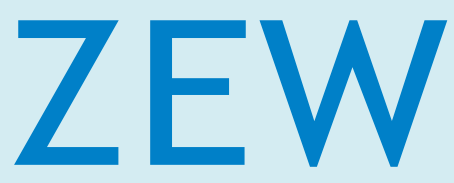

Zentrum für Europäische Wirtschaftsforschung $\mathrm{GmbH}$

Centre for European

Economic Research 
Discussion Paper No. 12-028

\section{Resale Price Maintenance and Manufacturer Competition for Retail Services}

Matthias Hunold and Johannes Muthers

Download this ZEW Discussion Paper from our ftp server:

http://ftp.zew.de/pub/zew-docs/dp/dp12028.pdf

Die Discussion Papers dienen einer möglichst schnellen Verbreitung von neueren Forschungsarbeiten des ZEW. Die Beiträge liegen in alleiniger Verantwortung der Autoren und stellen nicht notwendigerweise die Meinung des ZEW dar.

Discussion Papers are intended to make results of ZEW research promptly available to other economists in order to encourage discussion and suggestions for revisions. The authors are solely responsible for the contents which do not necessarily represent the opinion of the ZEW. 


\section{Non-technical summary}

Resale price maintenance (RPM) arises when a manufacturer fixes the price at which retailers resell the manufacturer's products. There is wide consensus among policymakers and economists that RPM can facilitate collusion among manufacturers and among retailers. RPM can also be used by a manufacturer to exclude more efficient rivals.

Yet the US Supreme Court overturned the long standing per-se illegality of minimum RPM with the Leegin decision of 2007. Courts now have to judge minimum RPM under the rule of reason. On the other side of the Atlantic, the European Commission decided to keep minimum and fixed RPM as core restrictions of competition in the renewed vertical block exemption of 2010, but the guidelines now specify when minimum RPM may be legal.

The dominant efficiency defense both in Leegin and the European guidelines are service incentives: A manufacturer uses minimum RPM to provide retailers with the appropriate incentives for socially desirable services that would be under-provided with price competition. The economic foundation of this argument rests on models with a single manufacturer. Yet in many RPM cases, including Leegin, competing manufacturers sell through common retailers.

With this paper, we shed light on the effects of RPM when competing manufacturers sell their products through common retailers who provide sales services. We set up a model which shows that if the competitive retail margins are low, each manufacturer fixes a minimum price to induce favorable retail services. With symmetric manufacturers, products are equally profitable in equilibrium and no product is favored, as without RPM, but retail prices are higher. We show that minimum RPM can create a prisoner's dilemma for manufacturers without increasing and possibly even decreasing the overall service quality.

Competition policy has to distinguish between cases in which externalities yield an insufficient level of retail services and cases in which the service level is sufficient or even better without RPM. The danger is that competition policy relies too much on the established service arguments with a single manufacturer, which suggest that minimum RPM increases efficiency. Within our model, raising retail margins of only one product through minimum RPM indeed induces retailers to allocate more services to that product. Hence a manufacturer can demonstrate that minimum RPM is effective in increasing services for its product. However, if our model applies, minimum RPM does not induce any efficiency gains in equilibrium, but increases retail prices and can even decrease the quality of service. 


\section{Das Wichtigste in Kürze}

Bei vertikaler Preisbindung legt der Hersteller den Preis fest, zu dem die Händler sein Produkt weiterverkaufen. Unter Wettbewerbsökonomen ist bekannt, dass dies Kollusion zwischen Herstellern sowie Händlern begünstigen kann. Auch kann ein Hersteller vertikale Preisbindung einsetzen, um effizientere Rivalen vom Absatzmarkt abzuschotten.

Dennoch hat der Oberste Gerichtshof der Vereinigten Staaten das Verbot vertikaler Fest- und Mindestpreisbindung mit der Leegin Entscheidung von 2007 aufgehoben und durch die Vernunftsregel (rule of reason) ersetzt, so dass nun fallweise über ihre Zulässigkeit entschieden wird. Die Europäische Kommission hat inzwischen entschieden, die Festund Mindestpreisbindung in der 2010 aktualisierten Vertikalen Gruppenfreistellungsverordnung weiterhin als Kernbeschränkungen des Wettbewerbs zu definieren. Jedoch nennt der neue Leitfaden nun ausdrücklich Fälle, in denen vertikale Preisbindung legal sein kann.

Die dominierende Effizienzverteidigung sowohl in der Leegin Entscheidung als auch im Leitfaden sind Anreize zu Händlerdienstleistungen: Ein Hersteller nutzt vertikale Mindestpreisbindung um verkaufsfördernde Händlerdienstleistungen anzubieten, die sozial wünschenswert sind und bei Preiswettbewerb zwischen den Händlern ungenügend angeboten würden. Allerdings basiert die ökonomische Fundierung dieses Arguments auf Modellen mit einem Hersteller, während in vielen Fällen vertikaler Preisbindung konkurrierende Hersteller Produkte über dieselben Händler vertreiben.

In diesem Papier analysieren wir daher den Fall konkurrierender, gleichartiger Hersteller mit gemeinsamen Händlern, die verkaufsfördernde Dienstleistungen wie Produktberatung anbieten. Wir zeigen anhand eines Modells, dass Hersteller dann Mindestpreise festlegen, wenn die Händlermargen bei Preiswettbewerb niedrig sind. Wenn die Hersteller gleichsam Preisbindung verwenden, dann sind die Produkte schließlich auch gleich profitabel und werden gleichmäßig mit verkaufsfördernden Maßnahmen ausgestattet. Jedoch sind die Verbraucherpreise höher als ohne Preisbindung, während die Qualität der verkaufsfördernden Maßnahmen niedriger sein kann. Wir zeigen zudem, dass die Möglichkeit vertikaler Preisbindung für die Hersteller kollektiv gewinnmindernd sein kann.

In der Wettbewerbspolitik sollte genau zwischen Fällen unterschieden werden, bei denen ohne Preisbindung zu wenige Händlerdienstleistungen angeboten werden, und Fällen, in denen genug und möglicherweise sogar bessere Dienstleistungen ohne Preisbindung angeboten werden. Wir sehen eine Gefahr darin, dass die Wettbewerbspolitik sich zu stark auf die etablierten, sogenannten Service-Argumente stützen könnte, die nahelegen, dass vertikale Mindestpreisbindung die Effizienz steigert. Bemerkenswerterweise führen in unserem Modell durch Preisbindung gestiegene Händlermargen eines Produktes dazu, dass die Händler diesem Produkt mehr verkaufsfördernden Maßnahmen zukommen lassen und es mehr verkaufen. Einseitig betrachtet kann ein Hersteller somit demonstrieren, dass Preisbindung effizienzsteigernde Effekte hat. Möglicherweise werden jedoch nur Händlerdienstleistungen von Produkten mit geringen zu denen mit hohen Margen verschoben und die Verbraucherpreise steigen, ohne dass die Qualität der Händlerleistungen zunimmt. 


\title{
Resale price maintenance and manufacturer competition for retail services*
}

\author{
Matthias Hunold ${ }^{\dagger}$ and Johannes Muthers ${ }^{\ddagger}$
}

April 16, 2012

\begin{abstract}
We investigate the incentives of manufacturers to use resale price maintenance (RPM) when selling products through common retailers. In our model retailers provide product specific pre-sales services. If the competitive retail margins are low, each manufacturer fixes a minimum price to induce favorable retail services. With symmetric manufacturers, products are equally profitable in equilibrium and no product is favored as without RPM, but retail prices are higher. We show that minimum RPM can create a prisoner's dilemma for manufacturers without increasing, and possibly even decreasing the overall service quality. This challenges the service argument as an efficiency defense for RPM.
\end{abstract}

JEL classification: D83, L42

Keywords: biased sales advice, common agency, manufacturer dilemma, matching, retail service, RPM, vertical restraints

*We thank participants at the JEI 2010, the MaCCI 2011 annual conference, the IIOC 2011, the IO Workshop Lecce 2011, the 2011 annual conferences of the EARIE and the Verein für Socialpolitik, and at seminars in Düsseldorf, Mannheim, Turunc and Würzburg, and in particular Firat Inceoglu, Martin Peitz, David Sauer, Norbert Schulz, Yossi Spiegel, Konrad Stahl and Sebastian Wismer for helpful comments and suggestions. This paper supersedes our earlier working paper circulated under the title "Resale Price Maintenance: Hurting Competitors, Consumers and Yourself".

${ }^{\dagger}$ ZEW Centre for European Economic Research, Mannheim and MaCCI, hunold@zew.de

‡University of Würzburg, johannes.muthers@uni-wuerzburg.de 


\section{Introduction}

There is a long controversy on whether resale price maintenance (RPM) should be legal. Although it is established that RPM facilitates collusion, ${ }^{1}$ the US Supreme Court overturned the long standing per-se illegality of minimum RPM with the Leegin decision of 2007. ${ }^{2}$ Courts now have to judge minimum RPM under the rule of reason. In the EU, minimum and fixed RPM are still core restrictions of competition, but the guidelines now specify when minimum RPM may be legal. ${ }^{3}$

The dominant efficiency defense both in Leegin and the European guidelines are service incentives: A manufacturer uses minimum RPM to provide retailers with the appropriate incentives for useful services that would be under-provided under price competition. Examples include shopping time reduction (Winter, 1993), quality certification (Marvel and McCafferty, 1984) and sales advice (Telser, 1960). These models focus on a single manufacturer, although we often observe minimum RPM at retailers carrying many brands of products such as books, clothing, contact lenses, hearing devices and household appliances. ${ }^{4}$ Retailers of such products frequently offer services such as pre-sales advice and product positioning. Interestingly, several observers have stated that the established service arguments often do not apply in RPM cases. ${ }^{5}$ Note that when retailers carry products of several manufacturers, a single manufacturer should have little incentives to use minimum RPM to finance retail services which benefit all manufacturers.

In this paper, we rationalize that minimum RPM may be used by competing manufacturers to divert retail services even when the overall service level of retailers cannot be affected. Note that for a fixed overall level of services, retailers should have incentives to allocate sales services more to those products on which they earn the highest margins. For example, the sales agent of a retailer, when approached by a consumer for sales advice, has to decide which product to present to the consumer. Although matching the consumers with on average less suitable products decreases overall sales, high retail margins on actual sales can outweigh this loss. In turn, each manufacturer has an incentive to use

\footnotetext{
${ }^{1}$ See Marvel and McCafferty, 1984; Jullien and Rey, 2007; Rey and Verge, 2010. RPM can also be used by a manufacturer to exclude more efficient rivals (Asker and Bar-Isaac, 2011 and references therein).

${ }^{2}$ Leegin Creative Leather Products, Inc. v. PSKS, Inc., 551 U.S., 2007. Minimum RPM implies that retailers may not sell below a specific price.

${ }^{3}$ Cf. Commission Regulation (EU) No 330/2010 (2010), Article 4a and the EU Guidelines on Vertical Restraints (2010/C 130/01); Paragraph 223 of the guidelines states that an efficiency defense in terms of Article 101,3 TFEU (Treaty on the Functioning of the European Union) is possible also for minimum and fixed RPM. Par. 224 and 225 contain examples of potentially detrimental and beneficial practices.

${ }^{4}$ See Elzinga and Mills (2009) for a discussion of services in the Leegin case. Other recent RPM cases with common retailers and products where pre-sale advice potentially matters include contact lenses (cf. fine "Bußgeldbescheid B 3 - 123/08," German Federal Cartel Office, September 2009), hearing devices (press release "Bundeskartellamt verhängt Bußgeld gegen Hörgerätehersteller Phonak GmbH," German Federal Cartel Office, October 2009.), and household appliances (cf. press release "Bundeskartellamt verhängt Bußgelder wegen unzulässiger Preisbindung," German Federal Cartel Office, 2003).

${ }^{5}$ Grimes (2009) states that "there has, in fact, been no case before the Supreme Court in which free riding was established as the motivation or justification for imposing RPM". Also see Supreme Court Judge Breyer (cf. fn. 2), Pitofsky (1984), SCHERER and ROSS (1990), pp. 551-552, and Klein (2009). Grimes (2009) points out that "an anticompetitive effect of RPM that has thus far escaped mention by the Supreme Court is its association with promotion that exploits consumer information gaps and, not infrequently, is misleading or fraudulent".
} 
minimum RPM to ensure high retail margins on its products and thereby increase their sales.

We set up a model with two symmetric manufacturers who sell through two common and symmetric retailers. The retailers allocate services among the products. First, we hold each retailer's overall service level fixed and assume that manufacturers do not compete directly for consumers, but only indirectly for favorable retail services. We show that if retail price competition is strong, each manufacturer fixes a minimum price to induce favorable services. This occurs even when only linear tariffs are feasible, so that a manufacturer cannot extract retail rents with a franchise fee.

Service is allocated evenly in equilibrium, just as without RPM. The retail prices are higher because with minimum RPM a manufacturer directly controls the retail margin and thus can incentivize favorable services without lowering its wholesale price. This exercise illustrates that minimum RPM may be used to boost sales services even though, by construction, the overall service level cannot increase.

Although total industry profits increase with minimum RPM, direct control can collectively hurt the manufacturers because competition for favorable services intensifies. Indeed, with linear wholesale tariffs and linear demand, minimum RPM implies a reduction in manufacturers' profits and benefits retailers. Nevertheless, manufacturers have individual incentives to use minimum RPM, which implies a prisoner's dilemma. On the contrary, maximum RPM - which manufacturers use if retail price competition is weak - increases both the manufacturer profits and consumer surplus, but decreases the retail profits.

In a second step, we allow each retailer to initially invest in the level of its matching services. Investing more yields more precise information about which product suits which consumer. Conventional wisdom suggests that if retailers need to invest in services, the service level should be higher because minimum RPM increases the retail margins. Contrarily, although sales are more profitable for a retailer, we find that equilibrium service investments are lower with minimum RPM. The reason is that retailers have ex-ante incentives to be uninformed about consumer preferences over the products, as this makes products more exchangeable from the retailers' perspective. Being more exchangeable induces the manufacturers to compete harder for favorable services and thus to offer more attractive tariffs to the retailers. With RPM, manufacturers compete more directly for favorable services. Thus retailers have stronger incentives to be uninformed when RPM is used, and invest less in matching precision.

In a third step, we allow for asymmetry by introducing a third manufacturer who offers a perfect substitute to one of the other manufacturers' products. As a consequence, only one manufacturer has market power, and only this manufacturer can effectively use RPM. The resulting asymmetric use of RPM tends to increase the asymmetry in margins and thus services. If retailers are close substitutes, consumers are inefficiently often matched with the high priced product. A ban on RPM can reduce this distortion.

Competition policy has to distinguish between cases in which externalities yield an 
insufficient level of retail services and cases in which the service level is sufficient or even better without RPM. The danger is that competition policy relies too much on the established service arguments with a single manufacturer, which suggest that minimum RPM increases efficiency. Within our model, raising retail margins of only one product through minimum RPM indeed induces retailers to allocate more services to that product. Hence a manufacturer can demonstrate that minimum RPM is effective in increasing services for its product. However, if our model applies, minimum RPM does not induce any efficiency gains in equilibrium, but increases retail prices and can even decrease the quality of service.

For example, in the Leegin case competing manufacturers of women apparel sold through common retailers. Elzinga and Mills (2009) defend Leegin's use of minimum RPM by stating that »Leegin's policy bears none of the marks of those economic theories of RPM that have anti-competitive effects«. Elzinga and Mills (2009) even emphasize the role of sales associates in the retailing of specialty apparel. ${ }^{6}$ With this paper, we contribute a theory of how minimum RPM, when used to increase sales services, can hurt all consumers - and even the manufacturers.

\section{Related literature}

This paper is related to the literature on service and RPM in the context of a single manufacturer. These arguments are based on positive service externalities. A retailer fails to take into account the positive effects of its services on the manufacturer's profits (Winter, 1993). Moreover, each retailer provides too little service if other retailers benefit from these services (Telser, 1960). A single manufacturer can mitigate these coordination failures by imposing RPM. It is acknowledged that a manufacturer optimizes services with respect to marginal consumers (Schulz, 2007). Nevertheless, it is often argued that the single manufacturer's interest with respect to margins and services of exclusive retailers are broadly aligned with the interests of an average consumer and thus total surplus. For a recent discussion see Winter (2009). ${ }^{7}$ We depart from the single manufacturer assumption and focus on the case of common retailers.

Our understanding that retailers can steer demand to more profitable products is related to the literature on product advice. Raskovich (2007) considers a setting with two manufacturers and a single retailer who provides product (existence) information. Raskovich assumes that manufacturers fully control retail margins, i.e., use RPM. Manufacturers compete in margins since the retailer has an incentive to inform consumers about high margin products rather than low margin products. He concludes that matching competition clauses may dampen competition. In Inderst and Ottaviani (2011), consumers

\footnotetext{
${ }^{6}$ Elzinga and Mills (2009) quote Bear Stearns Equity Research with "[I]t is critical that sales associates know the merchandise, have an understanding of the tastes and preferences of the target customer, and can offer fashion and wardrobing advice."

${ }^{7}$ Several articles study RPM in the context of spillovers in case of stock-outs (Deneckere et al., 1997, 1996; Krishnan and Winter, 2007; Wang, 2004). Wang actually has two manufacturers, but competitive exclusive retailers and finds that total surplus increases with RPM.
} 
shop for an experience good and have to rely on a single adviser. The adviser offers two products of two different firms and is paid by the firms through sales commissions. The firms compete in sales commissions to influence the advice and thereby boost demand. Inderst and Ottaviani find that commissions are higher when they are not disclosed, but that disclosure may lead to an inefficiently small market share of the more efficient product provider. As the adviser cannot set the retail prices, their setting is similar to our case where firms use RPM. ${ }^{8}$

These articles share with our paper that the matching advice offered by a retailer to customers is influenced by the products' profitabilities. However, these articles do not consider price competition between retailers and the incentives of a manufacturer to relax this competition by using RPM. The core of the present paper is the analysis of competing manufacturers' individual incentives to use RPM and the effects of RPM compared to a situation in which RPM is not feasible.

We are aware of two articles that also analyze RPM in a setting with differentiated manufacturers and common retailers, but neither considers service. Rey and Verge (2010) show that the monopolization result of Bernheim and Whinston (1985) with a common retailer and two-part tariffs offered by manufacturers can be extended to competing common retailers if manufacturers can use RPM. Their result relies on efficient two-part tariffs. $^{9}$ In addition, they point out that with two-part tariffs, common agency equilibria often fail to exist. Dobson and Waterson (2007) analyze bilateral Nash-bargaining between each manufacturer-retailer pair over a linear wholesale price. They find that if retailers have all the bargaining power, retail prices are higher with RPM. If, instead, manufacturers possess all the bargaining power, retail prices are higher without RPM because of double marginalization. Due to the model's complexity, Dobson and Waterson do not compare cases with intermediate bargaining power and do not analyze whether manufacturers would like to use RPM. ${ }^{10}$

\section{Model}

\subsection{Framework}

Two symmetric, differentiated, single-product manufacturers $(i=A, B)$ sell their products to two symmetric, differentiated retailers $(k=1,2)$. Retailers provide product specific services such as pre-sale advice. Services are non-contractible. We first assume that the overall service level, e.g., the number and skill of sales personnel used to advise consumers, is exogenous. Investments in the overall service level are endogenized in

\footnotetext{
${ }^{8}$ Moreover, Armstrong and Zhou (2011) show how a retailer affects the prominence of search goods. Dziuda (2011) shows that a biased expert can use strategic argumentation to mislead clients searching for the best match. Inderst and Ottaviani (2009a,b) analyze over-selling of a single product when retailers provide multiple services and biased advice with only one strategic producer and two products, respectively.

${ }^{9}$ Efficient means that rents can be extracted through up-front fees without a loss.

${ }^{10}$ Cf. Dobson and Waterson (2007), fn. 26.
} 


\section{Subsection 4.1 .}

For a fixed overall service level, we analyze how service is allocated to the products on offer. All costs of manufacturing and retailing are normalized to zero in this case. ${ }^{11} \mathrm{We}$ assume that more service allocated to product $i$ increases the demand for this product at both retailers. For a fixed overall service level, more service allocated to product $i$ implies a reduction in the service and thus demand for the other product, called $-i$. In particular, each retailer chooses $s_{k} \in[0,1]$, the fraction of services allocated to product $A$. If the retailer favors product $A(B), s_{k}$ is greater (smaller) than $1 / 2 ; s_{k}=1 / 2$ implies that retailer $k$ 's service is evenly distributed.

We assume that the allocation of services to products affects the maximal demand for each product at both retailers. $M_{i}$ is the maximal demand for product $i$ and depends on the service allocations of both retailers. Assume that demand for product $i$ at retailer $k$ is twice continuously differentiable and has the functional form

$$
D_{i, k} \equiv M_{i}\left(s_{k}, s_{-k}\right) d_{i, k}\left(p_{i, k}, p_{i,-k}\right)
$$

This demand structure allows us to separate the pricing of products from the service decisions. Demand for product $i$ only depends on the prices for that product at each retailer, but not on the prices of the other manufacturer's product. Thus, there is no direct price competition between the manufacturers. This ensures that manufacturers' strategic delegation of pricing to retailers à la Bonanno and Vickers (1988) and Rey and Stiglitz (1995) does not drive our results. We occasionally suppress the arguments when it is without loss of clarity and impose

Assumption 1. $M_{i}$ is strictly concave with $\frac{\partial M_{A}}{\partial s_{k}}>0>\frac{\partial M_{B}}{\partial s_{k}}$ and symmetric around $1 / 2$ : $M_{i}\left(s_{1}, s_{2}\right)=M_{-i}\left(1-s_{1}, 1-s_{2}\right) \cdot{ }^{12}$

The concavity and symmetry of $M_{i}\left(s_{1}, s_{2}\right)$ imply that allocating services unevenly to the two products reduces the aggregate $M_{A}+M_{B} \cdot{ }^{13}$ The service choice $s_{k}$ affects demand only through $M_{i}$. Hence, $s_{1}$ and $s_{2}$ affect both retailers symmetrically. This serves tractability, as does

Assumption 2. There are no cross effects between retailers' service allocations, in particular $M_{i}=M_{i, 1}\left(s_{1}\right)+M_{i, 2}\left(s_{2}\right)$.

Moreover, demand for a product decreases when all its retail prices increase:

Assumption 3. $\frac{\partial d_{i, k}}{\partial p_{i, k}}<0, \frac{\partial d_{i, k}}{\partial p_{i,-k}}>0$ and $\left|\frac{\partial d_{i, k}}{\partial p_{i, k}}\right|>\frac{\partial d_{i, k}}{\partial p_{i,-k}}$.

\footnotetext{
${ }^{11}$ Once service investments are endogenous the retailer must of course anticipate whether investment costs can be recovered.

${ }^{12}$ Strict concavity is convenient but our results are also valid as long as $a M_{i}+b M_{-i}$ is strictly quasiconcave for $a, b>0$ and $s_{1}, s_{2} \in(0,1)$. Strict quasi-concavity follows naturally from our micro foundation in Appendix B.

${ }^{13}$ The following assumptions on derivatives apply strictly only for the relevant range where $M_{i}$ and $d_{i, k}$ are positive. Strict concavity of $M_{i}$ in $s_{k}$ implies strict concavity of $M_{A}+M_{B}$. By symmetry, $M_{B}\left(s_{1}, s_{2}\right)=$ $M_{A}\left(1-s_{1}, 1-s_{2}\right)$. Thus $\frac{\partial}{\partial s_{k}}\left(M_{A}\left(s_{1}, s_{2}\right)+M_{B}\left(s_{1}, s_{2}\right)\right)=\frac{\partial}{\partial s_{k}}\left(M_{A}\left(s_{1}, s_{2}\right)+M_{A}\left(1-s_{1}, 1-s_{2}\right)\right)$. This derivative is zero at $s_{k}=0.5$. By strict concavity, this is the unique maximizer.
} 
As we assume service to be product specific, it is a form of special services discussed by Telser (1960). For example, retailers may provide information to consumers about the existence of the two products; each consumer only values one of the products and has limited patience. Naturally, each retailer has an incentive to first present the product which the consumer actually likes. If the retailer cannot say with certainty which product the consumer prefers, the retailer has to base its decision on an estimate of the probability that the consumer likes product A, and not B. When selling product A yields the same retail profit as selling product $B$, the retailer will always first present the product that is more likely to be valued by the consumer. Instead, if the products have different profitabilities, the retailer will more often present the product with the higher profitability.

In Appendix B, we provide a more formal exposition of this example of sales services, derive the properties of the demand function, and motivate the technical assumptions. Similar to Mathewson and Winter (1984), we assume that consumers are ex-ante not informed about the products, but know a product's retail prices once they are informed about it.

We are interested in the competitive effects of allowing the two manufacturers to control retail prices. Two regimes are considered:

(i) RPM is not enforceable by any manufacturer,

(ii) RPM can be enforced by each manufacturer.

If manufacturer $i$ restricts the retail price to $p_{i}$, it must be maintained by both retailers. ${ }^{14}$ The timing of the game is as follows:

1. Each manufacturer $i \in\{A, B\}$ sets a uniform wholesale price $w_{i}$, and optionally fixes $p_{i}$ under regime (ii).

2. Each retailer $k \in\{1,2\}$ observes all the prices set by manufacturers, chooses the service allocation $s_{k}$, and sets its own retail prices $p_{i, k}$. If RPM is enforced, $p_{i, k}$ is restricted to $p_{i}$.

3. Demand is realized.

Linear wholesale tariffs provide a clear-cut benchmark in which incentivizing retailers is costly for the manufacturers. Other things equal, imposing minimum RPM when additional rents can be extracted using up-front fees makes minimum RPM even more attractive. Moreover, with linear tariffs we avoid non-existence problems as in Rey and Verge (2010). Nevertheless, the logic of our arguments extends to non-linear contracts as well, see Subsection 5.1.

The profit of manufacturer $i$ is given by

$$
\pi_{i} \equiv w_{i} \sum_{k=1,2} D_{i, k}
$$

\footnotetext{
${ }^{14}$ We focus here on a symmetric treatment of the retailers, as is common in the literature on RPM. Within the present setting, this is also optimal for the manufacturers.
} 
and the profit of retailer $k$ by

$$
\Pi_{k} \equiv \sum_{i=A, B}\left(p_{i, k}-w_{i}\right) D_{i, k}
$$

To ensure that there is a unique equilibrium in the retailers' pricing game, we impose that the Hessian matrix of $d_{i, k}$ has a negative and dominant main diagonal.

Assumption 4. $\frac{\partial^{2} d_{i, k}}{\left(\partial p_{i, k}\right)^{2}} \leq 0, \frac{\partial^{2} d_{i, k}}{\left(\partial p_{i,-k}\right)^{2}} \leq 0, \frac{\partial^{2} d_{i, k}}{\partial p_{i, k} \partial p_{i,-k}} \geq 0,\left|\frac{\partial^{2} d_{i, k}}{\left(\partial p_{i, k}\right)^{2}}\right|>\frac{\partial^{2} d_{i, k}}{\partial p_{i, k} \partial p_{i,-k}} \cdot 15$

Now, we solve the game for subgame perfect Nash equilibria, first without and then with RPM. We begin with a brief discussion of a simple benchmark case with exogenous service allocations.

\subsection{A benchmark with exogenous service allocations}

Suppose for the moment that $s_{1}$ and $s_{2}$ are exogenous. As we assume that there is no direct price competition between the products $\mathrm{A}$ and $\mathrm{B}$, each manufacturer thus becomes an upstream monopolist facing two retailers under imperfect competition. Let superscript $N$ denote equilibrium prices without RPM. Without RPM, a double marginalization problem arises because the retail price $p^{N}$ lies above the monopoly price

$$
p^{M} \equiv \arg \max _{p} \sum_{k} p d_{i, k}(p, p)
$$

which maximizes industry profits. Manufacturers have no reason to incentivize retailers through positive margins as they cannot influence sales and a retailer's outside option is zero. Each manufacturer will consequently set its wholesale price equal to the monopoly price and use a price ceiling to squeeze the retail margin to zero, i.e., $w^{R}=p^{R}=p^{M}$, where superscript $R$ denotes equilibrium prices with RPM.

In what follows, we assume that retailers can steer demand by using the service instruments $s_{k}, k \in\{1,2\}$. Thus the product demands become interdependent and manufacturers have to compete for favorable retail services.

\subsection{Equilibrium without resale price maintenance (regime (i))}

Assume that manufacturers can only set wholesale prices, but that no manufacturer can use RPM. For given wholesale prices, each retailer chooses $p_{A, k}, p_{B, k}$ and $s_{k}$ to maximize $\Pi_{k}$. We first solve for retail prices and service allocations of the retail subgame. The first order condition (FOC) is

$$
\frac{\partial \Pi_{k}}{\partial p_{i, k}}=d_{i, k}+\left(p_{i, k}-w_{i}\right) \frac{\partial d_{i, k}}{\partial p_{i, k}}=0
$$

\footnotetext{
${ }^{15}$ The Assumptions 3 and 4 hold for example for the linear case, e.g. $d_{i, k}=1-(\beta+\gamma) p_{i, k}+\gamma p_{i,-k}$ with $\beta, \gamma>0$.
} 
Note that (5) is independent of $s_{1}$ and $s_{2}$ as well as of the wholesale and retail prices of product $-i$. Denote by $p_{i}^{*}\left(w_{i}\right)$ the equilibrium retail price for product $i$ and by

$$
\varphi_{i}^{*}\left(w_{i}\right) \equiv\left(p_{i}^{*}\left(w_{i}\right)-w_{i}\right) d_{i}\left(p_{i}^{*}, p_{i}^{*}\right)
$$

its corresponding retail profitability. Weak concavity and the dominance of own price effects of $d_{i, k}$ (Assumption 4) imply that the pass through $\partial p_{i}^{*} / \partial w_{i}$ is below one. Hence $\varphi_{i}^{*}$ decreases with $w_{i}$.

Differentiating $\Pi_{k}$ with respect to $s_{k}$ yields the FOC

$$
\frac{\partial \Pi_{k}}{\partial s_{k}}=\frac{\partial M_{i}}{\partial s_{k}}\left(p_{i, k}-w_{i}\right) d_{i, k}+\frac{\partial M_{-i}}{\partial s_{k}}\left(p_{-i, k}-w_{-i}\right) d_{-i, k}=0
$$

Retailer $k$ sets $s_{k}$ to shift demand towards the more profitable product. If the products are equally profitable, the strict concavity and symmetry of $M_{A}$ and $M_{B}$ imply that $s_{k}=1 / 2$ is optimal. Intuitively, each retailer maximizes the matches $M_{A}+M_{B}$ in this case. We denote by $s_{k}^{*}\left(w_{A}, w_{B}\right)$ the equilibrium service decisions as a function of the wholesale prices, by $M_{i}^{*}\left(w_{A}, w_{B}\right) \equiv M_{i}\left(s_{1}^{*}, s_{2}^{*}\right)$ the corresponding maximal demands and summarize in

Lemma 1. Without RPM, there exists a unique equilibrium in which both retailer decisions are the same. In particular

1. $p_{i}^{*}$ is an increasing function of $w_{i}$ and independent of $w_{-i}$ and $s_{k}$.

2. the retail profitability $\varphi_{i}^{*}\left(w_{i}\right)$ decreases in $w_{i}$.

3. an increase in $w_{i}$ decreases the equilibrium matches $M_{i}^{*}$ for product $i$.

4. for equal wholesale prices, service is allocated evenly, i.e., $s_{k}^{*}=1 / 2$.

Proof. All proofs are in Appendix A.

We can now turn to stage 1 . To simplify notation, let $d_{i}^{*}\left(w_{i}\right) \equiv \sum_{k} d_{i, k}\left(p_{i}^{*}\left(w_{i}\right), p_{i}^{*}\left(w_{i}\right)\right)$. Taking the retailer continuation equilibrium into account, a manufacturer's demand in stage 1 is given by $M_{i}^{*}\left(w_{i}, w_{-i}\right) d_{i}^{*}\left(w_{i}\right)$. Each manufacturer solves

$$
\max _{w_{i}} \pi_{i}=w_{i} M_{i}^{*}\left(w_{i}, w_{-i}\right) d_{i}^{*}\left(w_{i}\right)
$$

facing a tradeoff between price and quantity. An increase in $w_{i}$ increases the own margin, but decreases demand in two ways: First, the retail price increases so that some of the consumers attracted by services do not buy the product. Second, the retail profitability decreases so that retailers allocate services away and thus attract fewer consumers to the product as we show below. 
We derive the effect of $w_{i}$ on $M_{i}$ at symmetric wholesale prices $w^{N}$ by differentiating the retailer's FOC (6) for $s_{k}$ and evaluating it at $s_{k}=s_{k}^{*}$ and $p_{i, k}=p_{i}^{*}(w)$ :

$$
\frac{\partial M_{i}^{*}\left(w^{N}, w^{N}\right)}{\partial w_{i}}=\lambda \frac{\partial \varphi_{i}\left(w^{N}, w^{N}\right) / \partial w_{i}}{\varphi_{i}\left(w^{N}, w^{N}\right)}<0 .
$$

where

$$
\lambda \equiv \frac{\partial M_{i}(1 / 2,1 / 2) / \partial s_{k}}{M_{i}(1 / 2,1 / 2)} \times \frac{\partial M_{i}(1 / 2,1 / 2) / \partial s_{k}}{-\partial^{2} M_{i}(1 / 2,1 / 2) /\left(\partial s_{k}\right)^{2}}>0
$$

The parameter $\lambda$ is derived by collecting the effects of a change in $w_{i}$ through $s_{k}$ and $s_{-k}$ on $M_{i}$ at symmetric wholesale prices $w_{A}=w_{B}$. The first factor of $\lambda$ measures the relative shift in mass when $s_{k}$ is marginally changed at the point of symmetry. The second factor measures the curvature of $M_{i}$ at this point. The higher the second derivative is in absolute value, the more total mass is lost for a given shift. Thus, $\lambda$ measures the substitutability of the products as perceived by the retailers when they allocate services. The larger $\lambda$ is, the more substitutable the products are, and the less total mass is lost for a given shift.

The mass $M_{i}$ decreases more in the wholesale price $w_{i}$, the larger $\lambda$ is. This is because a retailer's opportunity costs of shifting demand decrease in $\lambda$ such that its reaction to a change in the relative profitabilities of the products becomes stronger. Substituting for $\partial M_{i}^{*}\left(w^{N}, w^{N}\right) / \partial w_{i}$ from (8) into the manufacturer's FOC implied by (7) and applying symmetry $w_{A}=w_{B}=w^{N}$ yields

$$
w^{N}=-\frac{d_{i, k}\left(p^{N}, p^{N}\right)}{\left(\sum_{k} \frac{\partial d_{i, k}}{\partial p_{i, k}}\right) \frac{\partial p_{i}^{*}}{\partial w_{i}}+\lambda\left(\frac{\partial d_{i, k}}{\partial p_{i, k}}+\frac{\partial d_{i, k}}{\partial p_{i,-k}} \frac{\partial p_{i}^{*}}{\partial w_{i}}\right)}
$$

with all derivatives evaluated at prices of $w^{N}$ and $p^{N}$. The retail price is characterized by

$$
p^{N}=p_{i}^{*}\left(w^{N}\right)=w^{N}-\frac{d_{i, k}\left(p^{N}, p^{N}\right)}{\partial d_{i, k}\left(p^{N}, p^{N}\right) / \partial p_{i, k}} .
$$

In what follows, we restrict attention to demand functions that give rise to quasi-concave reduced-form manufacturer profits and a stable equilibrium such that implicit differentiation of the manufacturer FOCs can be applied. ${ }^{16}$

Proposition 1. Without RPM, the symmetric equilibrium is unique and characterized by uniform wholesale prices of $w^{N}$ defined by (10), retail prices $p^{N}$ characterized by (11), and service allocations $s^{*}=1 / 2$. An increase in $\lambda$ reduces $w^{N}$ and $p^{N}$, but increases the retail profitability.

Intuitively, the more substitutable products are for a retailer, i.e., the higher $\lambda$ is, the more a retailer reallocates services in response to an increased profitability of a product.

\footnotetext{
${ }^{16}$ This is the case, for example, if $d_{i, k}$ is linear in prices and $M_{A}$ is of the form $\sum_{k} 2\left(s_{k}-s_{k}^{2} / 2\right)$. For a derivation of the latter, see the micro-foundation of demand in Appendix $B$.
} 
For $\lambda=0$, products are not substitutable and the equilibrium is that of the benchmark case in Section 3.2 where $M_{i}$ is exogenous and a manufacturer acts as an upstream monopolist. As $\lambda$ increases, manufacturer competition for favorable retail services drives wholesale prices towards zero and increases the retailers' profits.

\subsection{Equilibrium with resale price maintenance (regime (ii))}

In this subsection we first argue that if RPM is enforceable, both manufacturers will use it. Recall from Proposition 1 that if no manufacturer can use RPM, the equilibrium prices are $w^{N}$ and $p^{N}$. A manufacturer who unilaterally introduces RPM can reproduce the equilibrium prices without RPM by setting $p_{i}^{R}=p^{N}$ and $w_{i}^{R}=w^{N}$ and is thus at least as well off as without RPM. Manufacturer $i$ fixing both $w_{i}$ and $p_{i}$ faces the following tradeoffs:

- increasing $w_{i}$ increases its own margin, but decreases the retail margin $p_{i}-w_{i}$ and thus induces retailers to allocate services away from that product;

- increasing $p_{i}$ increases the retail margin and thus retailers allocate more services to product $i$. Yet a higher $p_{i}$ implies that an attracted consumer is less likely to buy the product.

Given the two instruments $\left(w_{i}, p_{i}\right)$, it is optimal for the manufacturer to enforce the industry profit maximizing retail price $p^{M}$. This price does not depend on the prices of the other product because there is no direct price competition between manufacturers. ${ }^{17}$ Summarizing:

Lemma 2. Each manufacturer has an individual incentive to use RPM and fix a retail price of $p^{M}$.

The economic intuition behind Lemma 2 is that the manufacturer can use RPM to maximize the joint rent from selling its product, and can use the wholesale price to control the retail margin and thus service incentives. Without RPM, the manufacturer can only use the wholesale price to control both retail incentives and overall profitability. Since it is a manufacturer's dominant strategy to use RPM and set the retail price at the monopoly level, both manufacturers will do so in any equilibrium in which both use RPM. The optimal wholesale price depends on the other product's retail profitability as this influences the service incentives. Focusing again on demands that give rise to interior solutions, yields

Proposition 2. In the unique and symmetric equilibrium with RPM,

$$
p^{R}=p^{M}, \quad w^{R}=\frac{p^{M}}{1+\lambda} .
$$

Service is allocated evenly and the retail margin increases in $\lambda$.

\footnotetext{
${ }^{17}$ Otherwise, the retail price would be a function of the competitor's retail price; see Subsection 5.2 for this extension.
} 
Having characterized the equilibrium prices and service decisions under both regimes, we now compare them to evaluate the effects of RPM on profits and welfare.

\subsection{Competitive effects of resale price maintenance}

For competition policy, an interesting question is whether RPM increases or decreases retail prices. Comparing the implicit characterizations of $p^{N}$ and $p^{R}=p^{M}$ yields

Lemma 3. The retail prices under $R P M, p^{M}$, are higher than the prices when no manufacturer uses $R P M, p^{N}$, if and only if

$$
\lambda>\lambda^{M} \equiv \frac{-\partial d_{i, k}\left(p^{M}, p^{M}\right)}{\partial p_{i, k}} / \frac{\partial d_{i, k}\left(p^{M}, p^{M}\right)}{\partial p_{i,-k}}-1 .
$$

Correspondingly, RPM decreases retail prices if and only if the above inequality is reversed. For $\lambda=\lambda^{M}, p^{N}=p^{M}$.

The right hand side of (13) measures the intensity of retail competition. It is positive as the own price effect dominates the cross price effect by Assumption 3. The left hand side of (13) contains $\lambda$, the substitutability of products for the retailers and thus measures manufacturer competition for services. With RPM, the retail price always equals $p^{M}$, whereas without RPM, the retail price decreases both in the intensities of manufacturer and retail competition. There is a critical level of $\lambda$, which we call $\lambda^{M}$, such that for a given intensity of retail price competition, the retail prices with and without RPM are equal. If competition at both levels is sufficiently intense, the price level without RPM is lower than the industry profit maximizing price level $p^{M}$, which results under RPM.

An important further question is whether minimum and maximum RPM can be distinguished with respect to their effects on retail prices and total surplus. We model RPM as price fixing. However, if RPM imposes a binding constraint on retailers, it acts either as a price floor or a price ceiling. For a given wholesale price, it is straightforward that minimum RPM increases retail prices while maximum RPM decreases prices. However, both wholesale and retail prices depend on whether RPM is used.

Minimum and maximum RPM can nevertheless be disentangled by answering the question: Does a retailer benefit from reducing or from increasing its price relative to the price imposed by the manufacturer? By evaluating a retailer's marginal profit with respect to its retail prices at the equilibrium values $\left\{w^{R}, p^{R}\right\}$, we obtain

Lemma 4. In equilibrium, manufacturers use minimum $R P M$ if and only if $\lambda>\lambda^{M}$. Manufacturers use maximum RPM if and only if $\lambda<\lambda^{M}$.

Corollary 1. Compared to the regime without RPM, minimum RPM always increases retail prices and maximum $R P M$ always decreases retail prices. The equilibrium allocation of services is not affected by RPM.

To see why using minimum RPM is equivalent to an increase in the retail price, note that at $\lambda=\lambda^{M}$, Lemma 4 implies $p^{*}\left(w^{R}\right)=p^{M}$, as no retailer has an incentive to 
deviate, whereas Lemma 3 implies $p^{N} \equiv p^{*}\left(w^{N}\right)=p^{M}$. This implies $w^{R}=w^{N}$ because $p^{*}(w)$ is strictly increasing in $w$. Without RPM, by an envelope argument, a marginal increase in $w_{i}$ above $w^{N}=w^{R}$ has no effect on the overall profitability of product $i$, as $p^{*}\left(w^{N}\right)=p^{M}$. Thus, locally, a change in the wholesale price $w_{i}$ boils down to a tradeoff between the manufacturer margin and the mass of demand $M_{i}$, which depends on the retail profitability. This is the same tradeoff a manufacturer faces when fixing $p_{i}=p^{M}$ and setting $w_{i}$. Hence at $\lambda=\lambda^{M}$, the equilibria with and without RPM coincide and RPM is a superfluous instrument. When raising $\lambda$ above $\lambda^{M}$, the wholesale prices both with and without RPM decrease (Propositions 1 and 2). In turn, RPM implies a price floor because each retailer individually prefers to set a price below $p^{M}$. Analogously, for $\lambda<\lambda^{M}$, wholesale prices increase and maximum RPM restricts the retail price to $p^{M}$ because retailers individually prefer to raise prices further.

Corollary 1 suggests a simple optimal policy which is to forbid minimum RPM as it unambiguously increases retail prices and leaves services unchanged. By construction, symmetric increases in the retail profitabilities have no welfare effect as they do not affect the overall service level that we have kept exogenous so far. This result provides a clear benchmark that minimum RPM is harmful if the retail service level for this product category is socially sufficient without RPM. In order to investigate the effects of RPM on service efforts, we allow for service investments in the next subsection.

Are manufacturers better off when minimum RPM is enforceable? Recall that a unilateral introduction of RPM is always weakly profitable for a manufacturer as it yields direct control over the retail margin (Lemma 2). However, this additional control induces manufacturers to compete harder for retail services. Collectively, manufacturers can thus be worse off, even if industry profits increase through RPM. The next lemma defines this case.

Lemma 5. The enforceability of RPM imposes a prisoner's dilemma on manufacturers when the equilibrium profit of a manufacturer under the regime (ii) with enforceable RPM is lower than under the regime (i) without RPM. This is equivalent to $w^{R} d_{i, k}\left(p^{R}, p^{R}\right)<$ $w^{N} d_{i, k}\left(p^{N}, p^{N}\right)$.

The inequality in Lemma 5 is independent of $M_{i}$ because $M_{i}$ is the same in any symmetric equilibrium. For the case of minimum RPM we have established that $p^{R}>p^{N}$ (Corollary 1 ); because $d_{i, k}$ decreases when both prices increase, $d_{i, k}\left(p^{R}, p^{R}\right)<d_{i, k}\left(p^{N}, p^{N}\right)$. Thus a sufficient condition for minimum RPM to lead to a prisoner's dilemma is $w^{R} \leq w^{N}$, i.e, that the manufacturer margin is weakly lower. Unfortunately, with only implicit definitions of $w^{R}$ and $w^{N}$, it is difficult to establish general conditions for $w^{R} \leq w^{N}$. In the next result, we use a linear parametrization of $d_{i, k}$ to obtain

Proposition 3. If demand is linear in prices, banning minimum RPM is both in the interest of consumers and manufacturers, whereas maximum RPM benefits these parties. For retailers, the reverse holds. 
Without RPM, each manufacturer incentivizes retailers to divert services by reducing the wholesale price. However, retailers partially pass the price reduction on to consumers. This effect dampens manufacturer competition for the services of retailers. By contrast, if manufacturers use minimum RPM, retailers cannot pass on the wholesale price reduction. Hence manufacturers compete more directly and thus more fiercely, yielding lower wholesale prices with RPM. For linear demand, using minimum RPM is collectively never in the interest of manufacturers.

A caveat applies as this result is derived for linear wholesale tariffs; with two-part tariffs, the manufacturer can generally extract retail rents with an upfront-payment. Yet with two-part tariffs, the manufacturer must ensure that the retailer prefers carrying its product over exclusively carrying the other product. This tradeoff and thus the retailer's outside option to carrying the product generally depend on whether RPM is used in the industry, hence it is an open question whether the dilemma ceases to exist. We further elaborate on non-linear tariffs in Subsection 5.1.

\section{Extensions}

\subsection{Investments in service quality}

For a fixed overall service level, as assumed so far, a natural measure of a retailer's service quality is the mass of consumers that is successfully matched by the retailer, i.e., $M_{i, k}\left(s_{k}\right)+M_{-i, k}\left(s_{k}\right)$. The equilibrium service quality does not depend on whether RPM is enforceable because the service allocations are always undistorted in equilibrium $\left(s_{k}^{*}=1 / 2\right)$. Conventional wisdom suggests that minimum RPM incentivizes retailers to invest more in service. We provide a counter example in which investment incentives of retailers are reduced when manufacturers use minimum RPM.

Consider that retail service consists of providing information about the existence of the products to consumers. Each consumer values only one of the products $A$ and $B$. Consumers are impatient: if the retailer first presents them with the product they do not value, they do not buy any product. The retailer does not perfectly know which product a consumer prefers. This micro-foundation is consistent with the demand function (1) used in the main part.

In this subsection, we additionally allow the retailer to invest in obtaining better information on consumer preferences. For example, the retailer can train the sales agents to be better informed about the products so that they know which product fits a given consumer's needs. Formally, each retailer's information is expressed by a posterior probability $q$ that a given consumer values product $B$ and not $A$. Investment in information affects the distribution of $q$, which we further specify below. We assume that retailers' investments take place in an initial stage and become public information before manufacturers set prices. This assumption implies that manufacturers can change prices more easily than retailer can change the service level. 
In what follows, we show that retailers invest less in service when manufacturers can use RPM than when manufacturers cannot use RPM. The reason is that the more a retailer invests, the better it is informed about each consumer's preferences and the less substitutable the products are when the retailer decides which product to present to a given consumer.

Let us establish this argument more formally. The probability $q$ that a consumer values product $B$ is distributed with $G$ over $[0,1]$. The information precision is captured by the size of the mass points $\alpha_{k} / 2$ at 0 and 1 . Assume that the mass of each consumer type at each retailer is one; hence $\alpha_{k}$ represents the share of consumers of each type for which the retailer knows the preferred product with certainty. To parametrize $G$, we additionally assume that $q$ is uniformly distributed in the interior $(0,1)$. The parameter $\alpha_{k}$ is thus the overall service level of a retailer: The higher $\alpha_{k}$ is, the better a retailer can match consumers to products. The mass of consumers successfully matched to product $A$ as a function of service levels and allocations is given by

$$
M_{i}\left(\alpha_{1}, \alpha_{2}, s_{1}, s_{2}\right) \equiv \sum_{k \in\{1,2\}} \alpha_{k}+\left(1-\alpha_{k}\right) \times 2 \times\left(s_{k}-s_{k}^{2} / 2\right) .
$$

The service allocation $s_{k}$ is the cut-off probability such that for higher $q$ the consumer is allocated to product $B$ instead of $A$. See Appendix B for a derivation of (14). Note that $M_{i}$ increases in $\alpha_{1}$ and $\alpha_{2}$ as the last term of (14) is smaller than one because $s_{k} \in[0,1]$.

Recall that retailers contribute to a pool of consumers $M_{i}$ for each product. ${ }^{18}$ For tractability, we maintain the assumption that manufacturers set uniform wholesale prices. The subgame equilibrium prices $\left(p^{N}, w^{N}, p^{R}, w^{R}\right)$ are only affected by $\alpha_{k}$ through $\lambda$ because $M_{i}$ does not directly affect the pricing of the products. For any $\alpha_{k}, k \in\{1,2\}$, equilibrium service allocations are $s_{k}^{*}=1 / 2$ as before. The relation between $\alpha_{k}$ and $\lambda$ is given by

$$
\lambda\left(\alpha_{1}, \alpha_{2}\right) \equiv \sum_{k} \frac{\left(1-\alpha_{k}\right)\left[\partial M_{i}(1 / 2,1 / 2) / \partial s_{k}\right]^{2}}{\left[\alpha_{k}+\left(1-\alpha_{k}\right) M_{i, k}(1 / 2,1 / 2)\right]\left[-\partial^{2} M_{i, k}(1 / 2,1 / 2) /\left(\partial s_{k}\right)^{2}\right]}
$$

with $\partial \lambda / \partial \alpha_{k}<0$. The arguments of $\lambda$ are suppressed from now on. Let $\widetilde{M}_{i}\left(\alpha_{1}, \alpha_{2}\right) \equiv$ $M_{i}\left(\alpha_{1}, \alpha_{2}, s_{1}=1 / 2, s_{2}=1 / 2\right)$. The equilibrium prices (with or without RPM) are denoted by $w^{l}(\lambda)$ and $p^{l}(\lambda)$ with $l=R, N$. Each retailer solves

$$
\max _{\alpha_{k}} \Pi_{k}=\sum_{i \in\{A, B\}} \widetilde{M}_{i}\left(\alpha_{k}, \alpha_{-k}\right)[\underbrace{\left(p^{l}(\lambda)-w^{l}(\lambda)\right) d_{i, k}\left(p^{l}(\lambda), p^{l}(\lambda)\right)}_{\text {retail profitability }}]-C\left(\alpha_{k}\right),
$$

where $C\left(\alpha_{k}\right)$ denotes the investment costs as a function of the overall service level. We assume that $C$ increases in $\alpha_{k}$ with $C^{\prime}(0)=0$ and $C^{\prime}(1)=\infty$ and is sufficiently convex to ensure unique solutions.

\footnotetext{
${ }^{18}$ This yields a public good problem among retailers, i.e., the well known free riding problem. Yet, we do not elaborate on it here as it is not central for this argument. A more detailed analysis of how consumers choose retailers providing matching advice is left for future research.
} 
Let us now inspect the tradeoffs a retailer faces when choosing $\alpha_{k}$ : More precise information on consumer types increase $\widetilde{M}_{i}$ and thus profits. As $\lambda$ decreases in $\alpha_{k}$, the wholesale prices increase with more precise information, both with and without RPM. Thus even without investment costs, the retailer faces a tradeoff: Better information increases successful matches and so demand, but it also decreases the retail profits earned on each consumer as the equilibrium wholesale prices increase. By investing less in precision, a retailer commits to perceive the products of the manufacturers as more substitutable, which invites the manufacturers to compete harder.

In order to compare the equilibrium quality levels with and without RPM, we use that $q$ is uniformly distributed in $(0,1)$ and let $d_{i, k}$ be linear in prices. ${ }^{19}$ Marginal profits $\frac{d \Pi_{k}}{d \alpha_{k}}$ are defined parametrically and we obtain

Proposition 4. If demand is linear and the uncertain information $q$ is uniformly distributed on $[0,1]$, the equilibrium service level $\alpha_{k}^{*}, k \in\{1,2\}$, and in turn quality is lower with RPM.

Intuitively, recall that the wholesale prices and hence retail profits depend on $\lambda$, which measures the degree of substitutability of the products. The more substitutable the products are, the higher is the retailer margin. By being less informed, the retailer chooses a higher $\lambda$ (more substitutability) and invites manufacturer competition. With RPM, each manufacturer can directly control its product's retail profitability by fixing the retail margin and can therefore respond more effectively to a change in $\lambda$. Hence, with RPM a higher $\lambda$ is more valuable for a retailer. As $\lambda$ decreases in $\alpha_{k}$, i.e. when the retailer is more informed, each retailer invests less in information precision under RPM.

\subsection{Asymmetric market power and resale price maintenance}

Symmetric manufacturers and retailers are a useful benchmark to assess the effects of RPM on prices and service levels. Moreover, it is insightful to consider manufacturers with different degrees of market power. We find that in such cases RPM tends to further distort the allocation of services.

Consider that there is one manufacturer of product $A$ as before, but that now there are two manufacturers of product $B$. Assume that a retailer's allocation of service on product $B$ cannot be manufacturer specific as the products are identical. In our leading example, this means that consumers who are informed about product $B$ may buy the product of either manufacturer of $B$. If RPM is ruled out, all three manufacturers only set wholesale prices in the first stage. Bertrand competition between the manufacturers of product $B$ forces wholesale prices to zero. This implies a retail price of $p^{*}(0)$ for product $B$ (Lemma 1$)$. Manufacturer $A$ earns positive profits by setting a positive wholesale price. As the retail profitability decreases in a product's wholesale price (Lemma 1), retailers will steer demand to product $B$ in equilibrium. Without RPM, retailers thus favor sales of the competitive product $B$.

\footnotetext{
${ }^{19}$ See Appendix B for a derivation of this $M_{i}$.
} 
Now assume that RPM is feasible. Interestingly, the manufacturers of product $B$ cannot effectively use RPM. By contradiction, assume that both manufacturers offer tariffs with wholesale prices of zero and a fixed retail price unequal to $p^{*}(0)$, i.e., effectively use RPM. This cannot be an equilibrium as a manufacturer of product B could profitably offer a contract with a slightly positive wholesale price and let retailers choose the price. Each retailer strictly prefers such an offer as it can play a best response to the other retailer.

Lemma 6. In any equilibrium, $w_{B}=0$ and $p_{B, 1}=p_{B, 2}=p^{*}(0)$. It is an equilibrium that each manufacturer of product $B$ offers $w_{B}=0$ and does not fix the retail price. ${ }^{20}$

Lemma 6 implies that the competing manufacturers for product $B$ cannot effectively use RPM. Hence the retail profitability on product $B$ is not affected by the enforceability of RPM.

The profitability of product $A$ generally depends on whether manufacturer $A$ uses RPM. Faced with the same equilibrium prices on product $B$ independent of whether $\mathrm{RPM}$ is feasible, manufacturer $A$ is clearly (weakly) better off when fixing the retail price. With RPM, manufacturer $A$ sets $p_{A}=p^{M}$ to maximize the overall profitability on product $A$ (Lemma 2 ) and sets $w_{A}$ by trading off the own margin and retailers' service incentives.

To understand the effects of RPM on prices and service allocations, consider two polar cases: retail monopolies and fierce competition (i.e., very small retail margins). In case of retail monopolies, the retail profitability is maximal on product $B$ and strictly smaller on product $A$ as $w_{A}>w_{B}=0$ and $p_{A}=p_{B}=p^{M}$. Thus service is (still) excessively allocated to product $B$, although excessive double marginalization on product $A$ is eliminated. By contrast, fierce retail competition implies that the profitability on product $B$ is low and, therefore, manufacturer $A$ uses RPM to raise the retail margin and thereby profitability of $A$ over that of $B$. Hence service is allocated more to product $A$ in equilibrium. In this case, RPM raises the price level of product $A$ and yields that services are allocated excessively to the more expensive product.

Proposition 5. Assume that two manufacturers sell product $B$ and one manufacturer sells product $A$. If RPM is not enforceable, service is allocated more to product $B$ than to the more expensive product A. If RPM is enforceable and retailers are close substitutes, product $A$ is more expensive than product $B$ and services are allocated more to product $A$.

The case with fierce retail competition and enforceable RPM exhibits that $A$ is sold at a high, manufacturer-maintained price and is favorably sold by retailers, whereas product $B$ is both less expensive and less endowed with services, e.g., is less advised or advertised. As an example for the asymmetry in manufacturer market powers, one could interpret $A$ as a branded product and $B$ as a private label which can be produced by several manufacturers. Interestingly, the price-service differential (high price \& high service vs. low price \&

\footnotetext{
${ }^{20}$ Both manufacturers of $B$ setting $w_{B}=0$ and fixing $p_{B}=p^{*}(0)$ is not necessarily an equilibrium as one manufacturer could offer $w_{B} \geq 0$ and fix a much higher $p_{B}$ and possibly be accepted by both retailers. In any case, there is no equilibrium in strictly mixed strategies with RPM.
} 
low service) is not caused by different product qualities (vertical differentiation), but by asymmetric market power at the manufacturer level.

\section{Discussion}

In the previous section, we characterized the equilibria with and without RPM and derived our main results under simplifying assumptions. In this section, we discuss the consequences of allowing for non-linear upstream tariffs and direct price effects between the products.

\subsection{Non-linear upstream tariffs}

We face the usual modeling tradeoff between linear and two-part tariffs. Whereas linear tariffs are sometimes bilaterally inefficient within the model framework, the efficiency of two-part tariffs rests on implicit simplifying assumptions such as no input arbitrage and risk neutrality of retailers. Although it seems plausible that contracts involve non-linear components such as rebate schemes, we believe that linear tariffs are often more reasonable than fully efficient two-part tariffs.

By using linear tariffs, we also avoid to confound the service effects with the commonagency effects pointed out by Rey and Verge (2010). These rely on two-part tariffs, as manufacturers need to become residual claimants of industry-profits. Our results with simple linear tariffs show that minimum RPM may even be used anti-competitively by manufacturers if more complex tariffs are not feasible.

Another reason for using linear tariffs is tractability. ${ }^{21}$ In a symmetric equilibrium with common retailers and manufacturers offering unconditional two part tariffs, each retailer has to be indifferent between accepting one or both contracts, as otherwise each manufacturer could raise the upfront payment. Denoting the candidate contract by $\{w, F\}$, the indifference condition becomes

$$
\sum_{i}\left[M_{i}\left(\frac{1}{2}, \frac{1}{2}\right)(p(w)-w) d_{i, k}(p, p)-F\right]=M_{i}\left(1, s^{d}\right)(p(w)-w) d(p, p)-F
$$

The left hand side contains the profit of a retailer when both retailers carry both products. The right hand side is the profit when the retailer only chooses one product, and retailers allocate services correspondingly. To break the indifference, a manufacturer can keep the upfront payment $F$ and lower its marginal price $w_{i}$ slightly below $w$ such that accepting only this manufacturer is strictly preferred by the retailer over accepting both. A marginal change thus induces a drastic reaction, which can destroy any candidate equilibrium. See Rey and Verge (2010) for a more detailed discussion on the non-existence of common agency equilibria in a similar setting. Conditional offers or menus of contracts may solve

\footnotetext{
${ }^{21}$ The assumption of linear wholesale contracts in a two-manufacturer-two-retailer framework is also made by Dobson and Waterson (2007).
} 
this problem. However, such an investigation is out of the scope of this paper. ${ }^{22}$

Nevertheless, focus we conjecture that our main results also hold with two-part tariffs. With two-part tariffs but without RPM, manufacturers can still not ensure high retail margins in case of strong retail competition. In turn, manufacturers have an incentive to reduce the wholesale margin in order to increase the retail profitability such that prices below the monopoly level may result. With RPM and two-part tariffs, providing marginal incentives is both feasible and costless as rents can be extracted via a fixed fee such that monopoly prices should be implemented.

Our result that RPM imposes a prisoner's dilemma relies on the assumption that a manufacturer cannot fully extract additional retail rents caused by RPM through twopart tariffs. However, note that in case of delegated agencies, also with two-part tariffs manufacturers must leave rents to retailers as a retailer can always opt to only carry one brand. A retailer's tradeoff between accepting one and both manufacturer's offers generally depends on whether RPM is employed. Thus RPM may impose a manufacturer dilemma even in case of fully efficient two-part tariffs.

\subsection{Direct inter-brand price competition}

The assumption of no cross price effects between products $A$ and $B$ simplified the previous exposition, but is certainly not always realistic. One way to relax this assumption is to assume that there is a fraction $1-\delta$ of uninformed consumers and a fraction $\delta$ of informed consumers.

An uninformed consumer only considers buying a product after being matched with that product by a retailer, giving rise to demand $d_{i, k}\left(p_{i, k}, p_{-i, k}\right) M_{i}\left(s_{k}, s_{-k}\right)$ as in the main part. Assume that informed consumers know their match values with both products, and that these values may both be positive. Hence the demand of an informed consumer, denoted by $h_{i, k}\left(p_{i, k}, p_{i,-k}, p_{-i, k} p_{-i,-k}\right)$, depends on all four prices, but not on service. Total demand is thus given by

$$
D_{i, k}=\delta h_{i, k}+(1-\delta) d_{i, k} M_{i}\left(s_{1}, s_{2}\right)
$$

A retailer's service allocation as a function of prices is still characterized by Equation (6) and thus remains unaffected. However, a retailer accounts for both $h_{i, k}$ and $d_{i, k}$ when deciding on a retail price $p_{i, k}$ and, therefore, considers the retail prices of product $-i$ which affect $h_{i, k}$. Similarly, a manufacturer now faces direct price competition through $h_{i, k}$. The equilibrium prices are a convex combination of the equilibrium prices when all consumers are informed $(\delta=1)$ and when all are uninformed $(\delta=0)$. By continuity of the objective functions in $\delta$, the results derived for $\delta=0$ in the main part remain qualitatively valid at least for a sufficiently small, but positive $\delta$.

Interestingly, another manufacturer dilemma may arise when the fraction of informed

\footnotetext{
${ }^{22}$ See Rey and Whinston (2011) on conditionality and menus when two retailers make offers to a single manufacturer.
} 
consumers $\delta$ is large. As $\delta \rightarrow 1$, the additional demand which can be generated with minimum RPM goes to zero. Instead, a manufacturer prefers maximum RPM to reduce the retail margin which increases demand through $h_{i, k}$ and $d_{i, k}$. Maximum RPM is a manufacturer's dominant strategy in the present timing (cf. Subsection 3.4).

However, committing not to control retail prices via RPM may increase profits as it can relax the manufacturers' competition: Without RPM on product $A$, the retailers may increase the price of product $A$ in response to a cost increase of product $B$; such a reaction induces manufacturer $B$ to set higher prices. See Bonanno and Vickers (1988) as well as Rey and Stiglitz (1995) who elaborate on strategic delegation of retail pricing in the context of exclusive retailers. Abstracting from direct price competition avoids to confound such effects with the effects of service competition.

\section{Conclusion}

In this paper, we analyze the incentives of manufacturers to use RPM when they compete for sales services provided by common retailers. A manufacturer can use RPM to protect the retailers' margins on its products to induce favorable services. Holding the overall service level constant, we show that in equilibrium the competition of symmetric manufacturers for retail services yields minimum RPM and higher retail prices. If retailers can invest in the overall service level, we show that retailers may invest less if minimum RPM is used, although retail margins are higher. In consequence, all consumers, and even manufacturers, can be worse off.

Our model features two manufacturers and two common retailers, endogenous wholesale and retail prices, as well as endogenous service allocations and levels. As the analysis of such a setting is inherently complicated when all four agents behave strategically, we have imposed several simplifying assumptions. First, we have focused on linear wholesale tariffs to avoid complications such as the non-existence of an equilibrium pointed out by Rey and Verge (2010). Second, we have not allowed for direct price competition between the competing products. Third, we have assumed that retailers contribute with their services to a common pool of consumers who are informed about the prices at both retailers. Although we have indicated that the assumptions can be relaxed without qualitatively changing the results, a full fledged analysis under alternative assumptions is beyond the scope of this paper, but appears promising for future research.

Service incentives are the major efficiency defense in favor of minimum RPM. In light of our results, we believe that competition policy relies too much on the established service arguments with a single manufacturer which - overall - suggest beneficial effects of minimum RPM. Similar arguments in favor of restricting retail price competition to ensure better consumer advice prevail in markets with complex products such as financial and health services. With this paper, we contribute a theory of how minimum RPM can hurt all consumers - and even manufacturers - in markets where manufacturers sell through common retailers who provide sales services. 


\section{Appendix A: Omitted proofs.}

Proof of Lemma 1. (1.) The FOC for the retail price is given by (5). The unique and symmetric equilibrium price $p_{i}^{*}$ is defined by applying symmetry to (5). Implicit differentiation yields $0<\frac{\partial p_{i}^{*}}{\partial w_{i}}<1, \frac{\partial p_{i}^{*}}{\partial w_{-i}}=0$.

(2.) $\frac{\partial}{\partial w_{i}}\left(\varphi_{i, k}\right)<0$ follows from $\frac{\partial}{\partial w_{i}}\left(p_{i}^{*}-w_{i}\right)<0$ and $\frac{\partial}{\partial p_{i}}\left(d_{i, k}\left(p_{i}^{*}, p_{i}^{*}\right)\right)<0$ (Assumption 3) in combination with $\frac{\partial}{\partial w_{i}}\left(p_{i}^{*}\right)>0$.

(3.) From (1.), retail prices do not depend on $s_{k}$. The equilibrium value $s_{k}^{*}$ is defined by the FOC (6) evaluated at $p_{i, k}=p_{i}^{*}\left(w_{i}\right) \forall i, k$. By symmetry, $s_{1}=s_{2}=s^{*}$ in equilibrium. Implicit differentiation of the definition of $s_{k}^{*}$ yields

$$
\frac{d s_{k}^{*}}{d w_{i}}=-\frac{\partial^{2} \Pi_{k}\left(p^{*}, p^{*}\right)}{\partial s_{k} \partial w_{i}} / \frac{\partial^{2} \Pi_{k}}{\partial^{2} s_{k}}=-\frac{\left(\frac{\partial \varphi_{i, k}}{\partial w_{i}} \frac{\partial M_{i}}{\partial s_{k}}\right)}{\frac{\partial^{2} M_{A}}{\left(\partial s_{k}\right)^{2}} \varphi_{A}+\frac{\partial^{2} M_{B}}{\left(\partial s_{k}\right)^{2}} \varphi_{B}} .
$$

$\frac{\partial^{2} \Pi_{k}}{\left(\partial s_{k}\right)^{2}}<0$ holds as $M_{i}$ is strictly concave. The sign of $\frac{d s_{k}^{*}}{d w_{i}}$ equals the sign of $\frac{\partial^{2} \Pi_{k}}{\partial s_{k} \partial w_{i}}=$ $\frac{\partial M_{i}}{\partial s_{k}} \frac{\partial \varphi_{i, k}}{\partial w_{i}}$. From (1.), $\frac{\partial \varphi_{i, k}}{\partial w_{i}}<0$. From Assumption $1 \frac{\partial M_{A}}{\partial s_{k}}>0>\frac{\partial M_{B}}{\partial s_{k}}$, hence, $\frac{d s^{*}}{d w_{A}}<0$ and $\frac{d s^{*}}{d w_{B}}>0$. Thus $\frac{\partial M_{i}^{*}}{\partial w_{i}}=\left[\frac{\partial M_{i}}{\partial s_{k}}+\frac{\partial M_{i}}{\partial s_{-k}}\right] \frac{\partial s^{*}}{\partial w_{i}}<0$ as the term in brackets is positive for $i=A$ and negative for $i=B$.

(4.) $w_{A}=w_{B} \equiv w$ implies equal retail price $p_{A}^{*}=p_{B}^{*}$ and thus equal profitabilities $\varphi_{A}\left(w_{A}\right)=\varphi_{B}\left(w_{B}\right) \equiv \varphi$. Hence $s^{*}=\arg \max _{s_{k}} M_{A} \cdot \varphi+M_{B} \cdot \varphi=\arg \max _{s_{k}} M_{A}+M_{B}=0$, i.e. service is allocated evenly.

Proof of Proposition 1. Differentiating a manufacturer's profit $\pi_{i}$ from (7) with respect to $w_{i}$ yields the FOC

$$
M_{i}^{*} d_{i}^{*}+w_{i} M_{i}^{*} \frac{\partial d_{i}^{*}\left(w_{i}\right)}{\partial w_{i}}+w_{i} d_{i}^{*}\left[\frac{\partial M_{i}}{\partial s_{k}} \frac{\partial s_{k}^{*}}{\partial w_{i}}+\frac{\partial M_{i}}{\partial s_{-k}} \frac{\partial s_{-k}^{*}}{\partial w_{i}}\right]=0
$$

with $\frac{\partial d_{i}^{*}\left(w_{i}\right)}{\partial w_{i}}=2\left(\frac{\partial}{\partial p_{i, k}}\left(d_{i, k}\left(p_{i}^{*}, p_{i}^{*}\right)\right)+\frac{\partial}{\partial p_{i,-k}}\left(d_{i, k}\left(p_{i}^{*}, p_{i}^{*}\right)\right)\right) \frac{\partial p_{i}^{*}\left(w_{i}\right)}{\partial w_{i}}$. Evaluating the FOC at $w_{A}=w_{B}=w^{N}$, and correspondingly $p_{A}=p_{B}=p^{N}$ and $s_{k}^{*}=0.5 \forall k$ as well as dividing by $2 M_{i}$ yields

$$
d_{i, k}\left(p^{N}, p^{N}\right)+w^{N}\left[\left(\frac{\partial d_{i, k}}{\partial p_{i, k}}+\frac{\partial d_{i, k}}{\partial p_{i,-k}}\right) \frac{\partial p_{i}^{*}}{\partial w_{i}}+\frac{d_{i, k}\left(p^{N}, p^{N}\right)}{M_{i}(0.5,0.5)}\left(\sum_{k} \frac{\partial M_{i}}{\partial s_{k}} \frac{\partial s_{k}^{*}}{\partial w_{i}}\right)\right]=0 .
$$

Moreover, (16) simplifies to $\frac{d s_{k}^{*}}{d w_{i}}=\frac{\frac{\partial}{\partial w_{i}}\left(\varphi_{i, k}\right)}{\varphi_{i}}\left(\frac{\partial M_{i}}{\partial s_{k}}\right) /\left(-\frac{\partial^{2} M_{A}}{\left(\partial s_{k}\right)^{2}}\right)$. Quasi-concavity of $\pi_{i}\left(w_{i}\right)$ implies that the above condition characterizes the equilibrium wholesale price. Solving for $w^{N}$ and substituting for $\frac{d s_{k}^{*}(1 / 2,1 / 2)}{d w_{i}}$ yields

$$
w^{N}=\frac{-d_{i, k}\left(p^{N}, p^{N}\right)}{\left(\frac{\partial d_{i, k}}{\partial p_{i, k}}+\frac{\partial d_{i, k}}{\partial p_{i,-k}}\right) \frac{\partial p_{i}^{*}}{\partial w_{i}}+d_{i, k} \cdot \frac{\partial \varphi_{i, k}}{\partial w_{i}} / \varphi_{i} \cdot\left(\sum_{k}\left(\frac{\partial M_{i}}{\partial s_{k}}\right)^{2} /\left(-2 \frac{\partial^{2} M_{i}}{\left(\partial s_{k}\right)^{2}} M_{i}(0.5,0.5)\right)\right)},
$$


Let $\lambda \equiv \sum_{k}\left(\frac{\partial M_{i}(1 / 2,1 / 2)}{\partial s_{k}}\right)^{2} /\left(-2 \frac{\partial^{2} M_{i}(1 / 2,1 / 2)}{\left(\partial s_{k}\right)^{2}} M_{i}(1 / 2,1 / 2)\right)$ and use that $d_{i, k} \cdot \frac{\partial \varphi_{i, k}}{\partial w_{i}} / \varphi_{i}=\frac{\partial d_{i, k}}{\partial p_{i, k}}+$ $\frac{\partial d_{i, k}}{\partial p_{i,-k}} \frac{\partial p_{i}^{*}}{\partial w_{i}}$ to reduce (18) to (10). Note that (9) follows from symmetry in $k$. Product $i$ 's retail profitability decreases in $w_{i}$ by Lemma 1 . To see that $\frac{d w^{N}}{d \lambda}<0$, implicitly differentiate the equilibrium FOC

$\frac{\partial \pi_{i}}{\partial w_{i}}=w^{N}\left\{\left(\frac{\partial d_{i, k}}{\partial p_{i, k}}+\frac{\partial d_{i, k}}{\partial p_{i,-k}}\right) \frac{\partial p_{i}^{*}}{\partial w_{i}}+\lambda\left[\frac{\partial d_{i, k}\left(p^{N}, p^{N}\right)}{\partial p_{i, k}}+\frac{\partial d_{i, k}\left(p^{N}, p^{N}\right)}{\partial p_{i,-k}} \frac{\partial p_{i}^{*}}{\partial w_{i}}\right]\right\}+d_{i, k}\left(p^{N}, p^{N}\right)=0$

to obtain

$$
\frac{d w^{N}}{d \lambda}=-\frac{\partial^{2} \pi_{i}\left(w^{N}, w^{N}\right)}{\partial w_{i} \partial \lambda} /\left(\frac{\partial^{2} \pi_{i}\left(w^{N}, w^{N}\right)}{\partial w_{i} \partial w_{i}}+\frac{\partial^{2} \pi_{i}\left(w^{N}, w^{N}\right)}{\partial w_{i} \partial w_{-i}}\right)
$$

Local stability implies $\frac{\partial^{2} \pi_{i}\left(w^{N}, w^{N}\right)}{\partial w_{i}^{2}}+\frac{\partial^{2} \pi_{i}\left(w^{N}, w^{N}\right)}{\partial w_{i} \partial w_{-i}}<0$. Moreover,

$$
\frac{\partial^{2} \pi_{i}}{\partial w_{i} \partial \lambda}=w^{N}\left[\frac{\partial d_{i, k}\left(p^{N}, p^{N}\right)}{\partial p_{i, k}}+\frac{\partial d_{i, k}\left(p^{N}, p^{N}\right)}{\partial p_{i,-k}} \frac{\partial p_{i}^{*}}{\partial w_{i}}\right]<0
$$

follows from Assumption (3) and $0<\frac{\partial p_{i}^{*}}{\partial w_{i}}<1$ (Lemma 1). Thus $\frac{\partial w^{N}}{\partial \lambda}<0$.

Proof of Lemma 2. As argued in the main part, using RPM is a dominant strategy for a manufacturer. Given wholesale and retail prices, each retailer chooses $s^{\prime}=\arg \max _{s_{k}} \Pi_{k}$. Let $\varphi_{i, k}\left(p_{i}, w_{i}\right)=\left(p_{i}-w_{i}\right) d_{i, k}\left(p_{i}, p_{i}\right)$. Implicit differentiation of $\partial \prod_{k} / \partial s_{k}=0$ yields

$$
\frac{\partial s^{\prime}}{\partial w_{i}}=\left(\frac{\partial M_{i}\left(s^{\prime}, s^{\prime}\right)}{\partial s_{k}} d_{i, k}\left(p_{i}, p_{i}\right)\right) /\left(\frac{\partial^{2} M_{i}\left(s^{\prime}, s^{\prime}\right)}{\left(\partial s_{k}\right)^{2}} \varphi_{i, k}+\frac{\partial^{2} M_{i}\left(-s^{\prime}, s^{\prime}\right)}{\left(\partial s_{k}\right)^{2}} \varphi_{-i, k}\right)
$$

and, analogously,

$$
\frac{\partial s_{k}^{\prime}}{\partial p_{i}}=\left(\frac{\partial M_{i}\left(s^{\prime}, s^{\prime}\right)}{\partial s_{k}} \frac{\partial \varphi_{i, k}}{\partial p_{i}}\right) /\left(\frac{\partial^{2} M_{i}\left(s^{\prime}, s^{\prime}\right)}{\left(\partial s_{k}\right)^{2}} \varphi_{i, k}+\frac{\partial^{2} M_{i}\left(-s^{\prime}, s^{\prime}\right)}{\left(\partial s_{k}\right)^{2}} \varphi_{-i, k}\right) .
$$

A manufacturer solves $\max _{w_{i}, p_{i}} \pi_{i}=w_{i} M_{i}\left(s_{k}, s_{-k}\right) \sum_{k} d_{i, k}\left(p_{i}, p_{i}\right)$, taking the prices $w_{-i}$ and $p_{-i}$ of the other product given. This yields the FOCs

$$
\begin{aligned}
\frac{\partial \pi_{i}}{\partial w_{i}}=2 d_{i, k}\left(p_{i}, p_{i}\right) M_{i}\left(s_{k}^{\prime}\right)+2 w_{i} d_{i, k}\left(p_{i}, p_{i}\right)\left(\frac{\partial M_{i}\left(s^{\prime}, s^{\prime}\right)}{\partial s_{k}} \frac{\partial s^{\prime}}{\partial w_{i}}\right) & =0 \\
\frac{\partial \pi_{i}}{\partial p_{i}}=2 w_{i}\left[\left(\frac{\partial d_{i, k}}{\partial p_{i, k}}+\frac{\partial d_{i, k}}{\partial p_{i,-k}}\right) M_{i}\left(s_{k}^{\prime}\right)+2 d_{i, k}\left(p_{i}, p_{i}\right)\left(\frac{\partial M_{i}\left(s^{\prime}, s^{\prime}\right)}{\partial s_{k}} \frac{\partial s_{k}^{\prime}}{\partial p_{i}}\right)\right] & =0
\end{aligned}
$$

Substitute from (19) and (20) in (21) and (22). Note that any linear combination of the above FOC must be zero at the point of the optimal prices, hence $\frac{\partial \pi_{i}}{\partial w_{i}}+c \frac{\partial \pi_{i}}{\partial p_{i}}=0 \forall c$. Setting $c=p_{i} / w_{i}$ implies $p_{i}\left(\frac{\partial d_{i, k}\left(p_{i}, p_{i}\right)}{\partial p_{i, k}}+\frac{\partial d_{i, k}\left(p_{i}, p_{i}\right)}{\partial p_{i,-k}}\right)+d_{i, k}\left(p_{i}, p_{i}\right)=0$. This is the FOC implied by (4) which holds if and only if $p_{i}=p^{M}$. 
Proof of Proposition 2. $p_{i}^{R}=p^{M}$ follows from Lemma 2. Summing up the FOCs (21) and (22) and imposing symmetry implies $w^{R}\left(\frac{\partial d_{i, k}\left(p^{M}, p^{M}\right)}{\partial p_{i, k}}+\frac{\partial d_{i, k}\left(p^{M}, p^{M}\right)}{\partial p_{i,-k}}\right)(1+\lambda)+d_{i, k}\left(p^{M}, p^{M}\right)=$ 0 . Rearranging and noting that $p^{M}=-d_{i, k}\left(p^{M}, p^{M}\right) /\left(\frac{\partial d_{i, k}\left(p^{M}, p^{M}\right)}{\partial p_{i, k}}+\frac{\partial d_{i, k}\left(p^{M}, p^{M}\right)}{\partial p_{i,-k}}\right)$ is implied by (4) yields $w^{R}=\frac{p^{M}}{1+\lambda}$. The wholesale price clearly decreases in $\lambda$ as $p^{M}$ is independent of $\lambda$. For $\lambda \rightarrow \infty, w^{R} \rightarrow 0$ and for $\lambda \rightarrow 0, w^{R} \rightarrow p^{M}$.

Proof of Lemma 3. The condition $p^{N}=p^{M}$ implies a $\lambda$ such that prices with and without RPM are equal. Substituting for $w^{N}$ from (10) and (11), and for $p^{M}$ from the FOC implied by (4), yields

$$
\frac{-d_{i, k}}{\left(\frac{\partial d_{i, k}}{\partial p_{i, k}}+\frac{\partial d_{i, k}}{\partial p_{i,-k}}\right) \frac{\partial p_{i}^{*}}{\partial w_{i}}+\lambda\left(\frac{\partial d_{i, k}}{\partial p_{i, k}}+\frac{\partial d_{i, k}}{\partial p_{i,-k}} \frac{\partial p_{i}^{*}}{\partial w_{i}}\right)}+\frac{-d_{i, k}}{\frac{\partial d_{i, k}}{\partial p_{i, k}}}=\frac{-d_{i, k}}{\frac{\partial d_{i, k}}{\partial p_{i, k}}+\frac{\partial d_{i, k}}{\partial p_{i,-k}}} .
$$

Note that all expressions with $d_{i, k}$ are evaluated at prices $p^{M}$ and $\frac{\partial p_{i}^{*}}{\partial w_{i}}$ at $w^{N}$. Isolating $\lambda$ yields

$$
\lambda=\frac{-\partial d_{i, k}\left(p^{M}, p^{M}\right) / \partial p_{i, k}}{\partial d_{i, k}\left(p^{M}, p^{M}\right) / \partial p_{i,-k}}-1=\lambda^{M} .
$$

To see that $\lambda \gtrless \lambda^{M}$ implies $p^{M} \gtrless p^{N}$, note that $p^{M}$ does not depend on $\lambda$, while $w^{N}$ decreases in $\lambda$ by Proposition 1 and $\frac{\partial p^{N}}{\partial w^{N}}=\frac{\partial p_{i}^{*}(w)}{\partial w}>0$ by Lemma 1 .

Proof of Lemma 4. Strict concavity of $\Pi_{k}$ in $p_{i, k}$ (this follows from weak concavity of $d_{i, k}$ ) implies that $\frac{\partial \Pi_{k}}{\partial p_{i, k}}$ is monotone in $p_{i, k}$. Consequently, if $\frac{\partial \Pi_{k}}{\partial p_{i, k}}$ is positive (negative) at $p_{i, k}=p_{i,-k}=p^{M}$, each retailer wants to increase (decrease) its price and thus RPM acts as maximum (minimum) RPM. Hence minimum RPM is equivalent to

$$
\frac{\partial d_{i, k}\left(p^{M}, p^{M}\right)}{\partial p_{i, k}}\left(p^{M}-w^{R}\right)+d_{i, k}\left(p^{M}, p^{M}\right)<0 .
$$

Add $0=\frac{\partial d_{i, k}}{\partial p_{i,-k}} p^{M}-\frac{\partial d_{i, k}}{\partial p_{i,-k}} p^{M}$ on the left hand side of the above to obtain

$$
\underbrace{\frac{\partial d_{i, k}}{\partial p_{i, k}} p^{M}+p^{M} \frac{\partial d_{i, k}}{\partial p_{i,-k}}+d_{i, k}}_{=0 \text { at } p^{M}}-w^{R} \frac{\partial d_{i, k}}{\partial p_{i, k}}-p^{M} \frac{\partial d_{i, k}}{\partial p_{i,-k}}<0 .
$$

Substitute $w^{R}=\frac{p^{M}}{1+\lambda}\left(\right.$ Proposition 2) to get $\lambda>\left[\frac{\partial d_{i, k}\left(p^{M}, p^{M}\right)}{\partial p_{i, k}} /-\frac{\partial d_{i, k}\left(p^{M}, p^{M}\right)}{\partial p_{i,-k}}\right]-1=\lambda^{M}$. 
Proof of Proposition 3. Let $d_{i, k}=1-(\beta+\gamma) p_{i, k}+\gamma p_{i,-k}$ with $\beta, \gamma>0$. Hence $\frac{\partial d_{i, k}}{\partial p_{i,-k}}=\gamma$, $\frac{\partial d_{i, k}}{\partial p_{i, k}}=-(\beta+\gamma), \frac{\partial d_{i, k}}{\partial p_{i, k}}+\frac{\partial d_{i, k}}{\partial p_{i,-k}}=-\beta$. Let the subscript $L I N$ denote prices of the linear demand case. $p_{i, L I N}^{*}(w)$ is obtained from substituting the linear demand expressions into (6) and letting $p_{i, 1}=p_{i, 2}=p$. This yields $1-\beta p+\gamma p+(p-w)(-\beta)=0$. Hence $p_{i, L I N}^{*}(w)=\frac{1+w(\beta+\gamma)}{2 \beta+\gamma}, \frac{\partial p_{i}^{*}}{\partial w_{i}}=\frac{\beta+\gamma}{2 \beta+\gamma}$, and $d_{i}^{*}(w) / 2=1-\beta \frac{1+w(\beta+\gamma)}{2 \beta+\gamma}$. Equilibrium prices are obtained by plugging the linear-demand analogs into the reduced form expressions (4), (10), (11), and (12). This yields $w_{L I N}^{N}=\frac{1}{2 \beta(1+\lambda)}, p_{L I N}^{N}=\frac{1+w^{N}(\beta+\gamma)}{2 \beta+\gamma}=\frac{1}{2 \beta+\gamma}\left(1+\frac{\beta+\gamma}{2 \beta(1+\lambda)}\right)$, $p_{L I N}^{R}=p_{L I N}^{M}=\frac{1}{2 \beta}$, and $w_{L I N}^{R}=\frac{p_{L I N}^{M}}{1+\lambda}=\frac{1}{2 \beta(1+\lambda)}$. Note that $w_{L I N}^{N}=w_{L I N}^{R}$, i.e. the wholesale price does not depend on the pricing regime. Thus the dilemma condition $w^{N} d_{i, k}\left(p^{N}, p^{N}\right)>w^{R} d_{i, k}\left(p^{M}, p^{M}\right)$ reduces to $d_{i, k}\left(p^{N}, p^{N}\right)>d_{i, k}\left(p^{M}, p^{M}\right)$ which is true if and only if $p^{N}<p^{M} \Longrightarrow \beta<\lambda^{2}$ as $\frac{\partial d_{i, k}}{\partial p_{i, k}}+\frac{\partial d_{i, k}}{\partial p_{i,-k}}=-\beta<0$.

Proof of Proposition 4. If the marginal profit $\frac{d \Pi_{k}}{d \alpha_{k}}$ with respect to $\alpha_{k}$ is higher without than with RPM, then the equilibrium service quality must be strictly higher without RPM. For $l=N, R$ the marginal profit is generally given by

$$
\sum_{i \in\{A, B\}} \frac{\partial \widetilde{M}_{i}}{\partial \alpha_{k}}\left(p^{l}(\lambda)-w^{l}(\lambda)\right) d_{i, k}\left(p^{l}\right)-C^{\prime}\left(\alpha_{k}\right)+\widetilde{M}_{i} \frac{d}{d \alpha_{k}}[\underbrace{\left(p^{l}(\lambda)-w^{l}(\lambda)\right) d_{i, k}\left(p^{l}(\lambda), p^{l}(\lambda)\right)}_{\text {retail profitability }}] .
$$

Differentiating the retail profitability under RPM yields

$$
\frac{d}{d \alpha_{1}}\left\{\left[p^{M} \cdot(1-1 /(1+\lambda)] d\left(p^{M}\right)\right\}=p^{M} d_{i, k}\left(p^{M}, p^{M}\right) /(1+\lambda)^{2} \cdot \frac{d \lambda}{d \alpha_{1}} .\right.
$$

In case of RPM, the retail price $p^{M}$, and thus also $d_{i, k}\left(p^{M}, p^{M}\right)$, is independent of $\lambda$. Hence only the retail margin increases in $\lambda$. The derivative without RPM is given by

$$
\frac{d}{d \alpha_{1}}\left[d_{i, k}\left(p^{N}, p^{N}\right)^{2}\left(-\frac{\partial d_{i, k}\left(p^{N}, p^{N}\right)}{\partial p_{i, k}}\right)^{-1}\right]=\frac{d\left[d_{i, k}\left(p^{N}, p^{N}\right)^{2} /\left(-\partial_{p_{i, k}} d_{i, k}\left(p^{N}, p^{N}\right)\right)\right]}{d p^{N}} \frac{d p^{N}}{d \lambda} \frac{d \lambda}{d \alpha_{1}}
$$

To determine which regime yields higher quality, we evaluate the sign of the difference in marginal profits without and with RPM, i.e. $\left.\frac{d \Pi_{k}}{d \alpha_{k}}\right|_{\mathrm{No}_{0}} \mathrm{RPM}-\left.\frac{d \Pi_{k}}{d \alpha_{k}}\right|_{\mathrm{RPM}}$ at symmetric investments $\left(\alpha_{1}=\alpha_{2}=\alpha\right)$. For this, substitute the equilibrium prices under linear demand (derived from $d_{i, k}=1-(\beta+\gamma) p_{i, k}+\gamma p_{i,-k}, \beta, \gamma>0$ in the proof of Lemma 3) and $\lambda$, which equals $\left(2-\alpha_{1}-\alpha_{2}\right)^{2} /\left(4-2 \alpha_{1}-2 \alpha_{2}\right)$ (obtained from plugging $M_{i}$ from (14) in the definition of $\left.\lambda\left(\alpha_{1}, \alpha_{2}\right)\right)$. The difference in marginal profits for $\alpha_{1}=\alpha_{2}=\alpha$, is then given by

$$
\frac{\alpha(10-\alpha)^{2}(\beta+\gamma)}{64(2 \beta+\gamma)^{2}}
$$

and straightforwardly shown to be positive for $0 \leq \alpha \leq 1, \beta>0$ and $\gamma>0$. 


\section{Appendix B: Micro foundation of service}

In this extension, we motivate the assumptions imposed on the reduced-form demand in Equation (1) by modeling retailers as matchmakers. The mass of consumers equals 4, so that each product at each retailer is maximally demanded by a unit mass of consumers. A consumer is of type $\theta \in\{A, B\}$ with $q_{0} \equiv \operatorname{Pr}(\theta=B)=\frac{1}{2}=\operatorname{Pr}(\theta=A)$. A consumer with type $\theta$ c.p. prefers product $i=\theta$ over $i \neq \theta$, as specified below. Whereas $q_{0}$ is common knowledge, an individual consumer's type and its valuations are ex ante unknown to everybody.

After all prices are set, assume that the game proceeds as follows: Initially consumers are neither informed about the existence nor the match value of the two products and hence randomly visit a retailer. Once a consumer seeks advice at a retailer, the retailer receives a private information about the consumer's type. This information is captured by the cumulative distribution function of the retailer's posterior belief, $G(q)$, with full support $q \in[0,1]$. As products $A$ and $B$ are symmetric, we naturally assume that $q$ is distributed symmetrically around 0.5. For convenience we stipulate that $G(q)$ is twice continuously differentiable in the interior; its density is denoted by $g(q)$. We allow for mass points at the borders 0 and 1. In Subsection 4.1, the size of the retailer specific mass point is symmetric at zero and 1 and equals $\alpha_{k} / 2{ }^{23}$

A consumer of type $\theta$ who is matched by a retailer with the suitable product $i=\theta$ (a "good match") draws his retailer dependent valuations for that product $v_{i, k}, k \in\{1,2\}$, from a joint distribution with the density function $h\left(v_{i, k}, v_{i,-k}\right)$. Instead, if the consumer is matched with product $i \neq \theta$, he draws a valuation of 0 with probability 1 . Thus only consumers who have been presented with a suitable product consider buying the product. We assume that a consumer who has been presented with an unsuitable product stops his search. This assumption is reasonable, for example, if asking a second retailer advice is relatively costly for consumers. Moreover, if both retailers receive the same information upon advising a consumer, the consumer can only get a different second advice if the retailers use the information differently.

As there are two retailers, a mass of consumers of $4 / 2=2$ visit retailer $k$. Each retailer matches one product to each consumer in his shop. After the matching each consumer buys one unit of the matched product at one retailer or nothing at all. We assume that a consumer has no cost for obtaining information on the prices at both retailers once he knows his preferred product. By this we abstract from modeling price search explicitly. Low search costs for prices, once the product identity is known, are reasonable for example if price information can be obtained on the Internet. The consumer buys at retailer $k$ if and only if $v_{i, k}-p_{i, k} \geq \max \left(v_{i,-k}-p_{i,-k}, 0\right)$. Integrating this condition over $v_{i, k}$ and $v_{i,-k}$

\footnotetext{
${ }^{23}$ The distribution $G$ can equivalently be derived from Bayesian updating of the prior conditional on a signal $\sigma$ with informative conditional distributions $F_{i}(\sigma \mid \theta=i)$.
} 
yields the probability of a sale conditional on a correct match, which is given by

$$
d_{i, k}=\int_{p_{i, k}}^{\infty} \int_{-\infty}^{v_{i, k}-p_{i, k}+p_{i,-k}} h\left(v_{i, k}, v_{i,-k}\right) d v_{i,-k} d v_{i, k}
$$

This demand formulation has the property that demand decreases when all prices increase, in particular $\frac{\partial d_{i, k}}{\partial p_{i, k}}<0$ and $\frac{\partial d_{i, k}}{\partial p_{-i, k}}>0$ where $h$ is not zero. ${ }^{24}$ Our assumptions on higher order derivatives, in particular, the negative dominant diagonal of the Hessian of $d_{i, k}$ can be met by choosing an appropriate density $h$. Demand at retailer $k$ for product $i$ equals $M_{i}$, i.e. the mass of consumers who have been presented with product $i$ and are of type $i$, times $d_{i, k}$, the price-dependent sales probability of that retailer.

The product presentation boils down to each retailer choosing a threshold probability $s_{k}$, such that the retailer presents consumers with product $A$ and for $q<s_{k}$ and with product $B$ for $q>s_{k} \cdot{ }^{25}$ The mass of consumers who are correctly matched with product $i$ by retailer $k$ is thus given by

$$
\begin{aligned}
& M_{A, k}=\alpha_{k}+2 \int_{0}^{s_{k}}(1-q) g(q) d q \\
& M_{B, k}=\alpha_{k}+2 \int_{s_{k}}^{1} q g(q) d q .
\end{aligned}
$$

Note that $s_{k}=1$ implies that the retailer informs all consumers about product $A$. Half of these consumers are actually of type $A$ this yields $M_{A, k}=1$. As $v_{i, k}$ does not depend on where the consumer was advised, demand for $i$ at $k$ is given by $D_{i, k} \equiv$ $\left[M_{i, 1}\left(s_{1}\right)+M_{i, 2}\left(s_{2}\right)\right] d_{i, k}=M_{i} d_{i, k} \cdot{ }^{26}$ Note that $M_{i}$ consists of the sum of the consumers correctly matched with $i$ at each retailer and thus satisfies Assumption 2. $M_{i, k}$ and hence $M_{i}$ are monotone in $s_{k}$ as stipulated in Assumption 1, that is, $\frac{\partial M_{A}}{\partial s_{k}}=\sum_{k} \frac{\partial M_{A, k}}{\partial s_{k}}=$ $\sum_{k} 2\left(1-s_{k}\right) g\left(s_{k}\right)>0$ and $\frac{\partial M_{B}}{\partial s_{k}}=\sum_{k} \frac{\partial M_{B, k}}{\partial s_{k}}=\sum_{k} 2(-q g(q))<0$. Furthermore, for $a, b>0$ and interior $s_{k} \in(0,1)$ (so that $M_{i}>0 \forall i$ ), $a M_{A, k}+b M_{B, k}$ is strictly quasi concave. In particular, it is strictly increasing for $s_{k}<\frac{a}{a+b}$ and strictly decreasing for $s_{k}>\frac{a}{a+b}$. For $a=b$, it is maximized at $s_{k}=0.5$. To see this, note that $a M_{A, k}^{\prime}+b M_{B, k}^{\prime}=\left(a-(a+b) s_{k}\right) g$.

In this context, $\lambda$ as defined in (9) is a measure of information precision. Note that $\frac{\partial^{2} M_{i}\left(\frac{1}{2}, \frac{1}{2}\right)}{\left(\partial s_{k}\right)^{2}}=-g$ as $g^{\prime}\left(\frac{1}{2}\right)=0$ by symmetry of $G$. Substituting the expressions just derived into the definition of $\lambda$ yields $\lambda=2 \frac{g\left(\frac{1}{2}\right)}{M_{i}\left(\frac{1}{2}, \frac{1}{2}\right)}$. With better information, $g$ becomes more dispersed, that is, $g\left(\frac{1}{2}\right)$ decreases, whereas $M_{i}\left(\frac{1}{2}, \frac{1}{2}\right)$ increases when the more informative $q$, i.e., those closer to zero and those closer to one are drawn more frequently. ${ }^{27}$ For example, if the mass point $\alpha_{k}$ increase and $g$ is uniform in the interior, the density decreases everywhere in $(0,1)$.

\footnotetext{
${ }^{24}$ This discrete choice demand is consistent with locally linear demand. Yet if $h$ has full support, demand cannot be globally linear in prices, see Jaffe and Weyl (2010) for a detailed discussion.

${ }^{25}$ There is no reason for a retailer to present product $A$ to a consumer when he has a belief $q^{\prime}>q$ and $B$ to a consumer with $q$.

${ }^{26}$ Though not necessary, this assumption greatly simplifies as retail pricing is independent of services.

${ }^{27}$ Cf. Ganuza and Penalva (2010) on information precision and Inderst and Ottaviani (2011) for a similar application.
} 
In the main body of this paper we sometimes use an explicit formulation of $M_{A}$ and $M_{B}$ that is derived under the assumption that $G$ is uniform on $(0,1)$. Solving the integrals in (26) and (27) for $g=\left(1-\alpha_{k}\right)$ and summing over $k$ directly yields

$$
\begin{aligned}
& M_{A}=\alpha_{1}+\left(1-\alpha_{1}\right) 2\left(s_{1}-s_{1}^{2} / 2\right)+\alpha_{2}+\left(1-\alpha_{2}\right) 2\left(s_{2}-s_{2}^{2} / 2\right), \\
& M_{B}=\alpha_{1}+\left(1-\alpha_{1}\right) 2\left(1 / 2-s_{1}^{2} / 2\right)+\alpha_{2}+\left(1-\alpha_{2}\right) 2\left(1 / 2-s_{2}^{2} / 2\right) .
\end{aligned}
$$

Moreover, if $G$ is uniform, $M_{i}, M_{i, k}$ and $a M_{A, k}+b M_{B, k}$ (with $a, b>0$ ) are strictly concave for $s_{k} \in(0,1)$.

\section{References}

Armstrong, M. and J. Zhou, "Paying for Prominence," The Economic Journal, 2011, 121 (556), 368-395.

Asker, J. and H. Bar-Isaac, "Exclusion due to RPM, Slotting Fees, Loyalty Rebates and other Vertical Practices," 2011.

Bernheim, B.D. and M.D. Whinston, "Common Marketing Agency as a Device for Facilitating Collusion," RAND Journal of Economics, 1985, 16 (2), 269-281.

Bonanno, G. and J. Vickers, "Vertical separation," The Journal of Industrial Economics, 1988, 36 (3), 257-265.

Deneckere, R., H.P. Marvel, and J. Peck, "Demand uncertainty, inventories, and resale price maintenance," The Quarterly Journal of Economics, 1996, 111 (3), 885-913.

$\ldots, \ldots$, and _ , "Demand uncertainty and price maintenance: markdowns as destructive competition," The American Economic Review, 1997, 87 (4), 619-641.

Dobson, P.W. and M. Waterson, "The competition effects of industry-wide vertical price fixing in bilateral oligopoly," International Journal of Industrial Organization, 2007, 25 (5), 935-962.

Dziuda, W., "Strategic argumentation," Journal of Economic Theory, 2011, 146 (4), 1362.

Elzinga, K. and D. Mills, "The Economics of resale Price maintenance," ISSUES IN COMPETITION LAW AND POLICY (3-Volume Set), Kenneth G. Elzinga \& David E. Mills, eds., ABA Section of Antitrust Law, 2008, 2009.

Ganuza, J.J. and J.S. Penalva, "Signal orderings based on dispersion and the supply of private information in auctions," Econometrica, 2010, 78 (3), 1007-1030.

Grimes, W., "Resale Price Maintenance: A Competitive Assessment," Federal Trade Commission Workshop on Resale Price Maintenance Panel on Anticompetitive Effects, 2009, pp. 27-30. 
Inderst, R. and M. Ottaviani, "How (not) to pay for advice: A framework for consumer protection," 2009.

_ and _ , "Misselling through agents," The American Economic Review, 2009, 99 (3), 883-908.

_ and _, "Competition through Commissions and Kickbacks," The American Economic Review forthcoming, 2011.

Jaffe, S. and E.G. Weyl, "Linear Demand Systems are Inconsistent with Discrete Choice," The BE Journal of Theoretical Economics, 2010, 10 (1), 52.

Jullien, B. and P. Rey, "Resale price maintenance and collusion," The RAND Journal of Economics, 2007, 38 (4), 983-1001.

Klein, B., "Competitive Resale Price Maintenance in the Absence of Free-Riding," Antitrust Law Journal, Vol. 76, No. 2, 2009, 2009.

Krishnan, H. and R.A. Winter, "Vertical control of price and inventory," The American Economic Review, 2007, 97 (5), 1840-1857.

Marvel, H.P. and S. McCafferty, "Resale price maintenance and quality certification," The RAND Journal of Economics, 1984, 15 (3), 346-359.

Mathewson, G. F. and R.A. Winter, "An Economic Theory of Vertical Restraints," The RAND Journal of Economics, 1984, 15 (1), pp. 27-38.

Pitofsky, R., "Why Dr. Miles was right," Journal on gouverment and society, 1984.

Raskovich, A., "Retail buyer power through steering," Economics Letters, 2007, 96 (2), 221-225.

Rey, P. and J. Stiglitz, "The role of exclusive territories in producers' competition," The RAND Journal of Economics, 1995, 26, 431-451.

- and M.D. Whinston, "Does Retailer Power Lead to Exclusion?," IDEI Working Papers, 2011.

- and T. Verge, "Resale Price Maintenance and Interlocking Relationships," The Journal of Industrial Economics, 2010, 58 (4), 928-961.

SCHERER, FM and D. ROSS, "Industrial market structure and economic performance..," 3. ed., 1990.

Schulz, N., "Does the Service Argument Justify Resale Price Maintenance?," Journal of Institutional and Theoretical Economics JITE, 2007, 163 (2), 236-255.

Telser, L.G., "Why should manufacturers want fair trade?," Journal of law and economics, 1960, 3, 86-105. 
Wang, H., "Resale price maintenance in an oligopoly with uncertain demand," International Journal of Industrial Organization, 2004, 22 (3), 389-411.

Winter, R., "Vertical control and price versus nonprice competition," The Quarterly Journal of Economics, 1993, 108 (1), 61-76.

Winter, R.A., "Presidential Address: Antitrust restrictions on single-firm strategies," Canadian Journal of Economics/Revue canadienne d'économique, 2009, 42 (4), 12071239. 